\title{
Spatio-Temporal Trend Mapping of Precipitation and its Extremes Across Afghanistan (1951-2010)
}

\section{Quarban Aliyar}

Bamyan University

Santosh Dhungana ( $\nabla$ santosh.dhung@gmail.com )

Asian Institute of Technology https://orcid.org/0000-0003-2549-2390

\section{Sangam Shrestha}

Asian Institute of Technology

\section{Research Article}

Keywords: Precipitation, extreme indices, trend, variability, Mann-Kendall, Sen's slope

Posted Date: September 3rd, 2021

DOI: https://doi.org/10.21203/rs.3.rs-511008/v1

License: (1) This work is licensed under a Creative Commons Attribution 4.0 International License. Read Full License

Version of Record: A version of this preprint was published at Theoretical and Applied Climatology on November 12th, 2021. See the published version at https://doi.org/10.1007/s00704-021-03851-2. 


\title{
Spatio-temporal trend mapping of precipitation and its extremes across Afghanistan (1951-2010)
}

\author{
Qurban Aliyar ${ }^{1}$ Santosh Dhungana ${ }^{2}$ Sangam Shrestha ${ }^{3}$ \\ ${ }^{1}$ Department of Forestry and Natural Resources, Faculty of Agriculture, Bamyan University, Bamyan 1601, \\ Afghanistan; q.aliyar@bu.edu.af \\ ${ }^{2,3}$ Water Engineering and Management, School of Engineering and Technology, Asian Institute of Technology, P.O. \\ Box 4 Klong Luang, Pathum Thani, 12120, Thailand.
}

\section{Corresponding author}

Santosh Dhungana

Email: santosh.dhung@gmail.com

ORCID: 0000-0003-2549-2390

\begin{abstract}
The civil war, harsh climate, tough topography and lack of accurate meteorological stations has limited observed data across Afghanistan. In order to fulfill the gap, this study analyzed the trend in precipitation and its extremes using Asian Precipitation Highly Resolved Observational Data Integration Towards Evaluation (APHRODITE) daily dataset between 1951 to 2010 at the spatial resolution of $0.25^{\circ} 0.25^{\circ}$. Non-parametric modified Mann-Kendall test and Sen's slope estimator were employed to detect trend and quantify it at the significance level of 5\%. Significant decreasing trends were observed only in small clusters of southwestern regions ranging between 0 to $-1.5 \mathrm{~mm} /$ year and northeastern region between -1.5 to $-6 \mathrm{~mm} /$ year for the annual time series. Similar trend pattern was observed in spring season decreasing at the rate of -0.15 to $0.54 \mathrm{~mm} /$ year in northeastern and 0 to $-0.15 \mathrm{~mm} /$ year southwestern region. Decrease in spring precipitation is expected to affect crop production especially in northeastern region which host 22 $\%$ of the arable area. Increasing trend in eastern region at maximum of $0.16 \mathrm{~mm} / \mathrm{year}$ was observed which could intensify the flooding events. Trend analysis of extreme precipitation indices indicated similar spatial distribution to the mean precipitation, concentrated around southwestern, northeastern, and eastern regions. Increasing frequency of consecutive dry days in western region and very heavy precipitation (R10mm) and extremely heavy precipitation $(\mathrm{R} 20 \mathrm{~mm})$ in eastern region are fueling the occurrence of droughts and floods respectively. Taking these findings of erratic nature of rainfall and extreme events into consideration for sustainable management of water resources would be fruitful.
\end{abstract}

Keywords: Precipitation, extreme indices, trend, variability, Mann-Kendall, Sen’s slope

\section{Introduction}

Precipitation is one of the most important variables in hydrology that directly influences the hydrologic processes. Change in precipitation has direct effect on water resources, agriculture, forestry, ecosystem, natural resources, plant cover and drinking water (Cannarozzo et al. 2006). Because of this, it has garnered wider attention of scientific communities in light of climate change. Intensification of extreme precipitation events in frequency, duration and intensity are recurrent with global warming than the mean precipitation and are expected to continue in future (Myhre et al. 2019). Escalation in extreme events aggravate the frequency of floods/droughts (Easterling et al. 2000) which disrupts socio-economic balance affecting every aspect of human activities. Assessing the trend of climatic variables plays a pivotal role in assessing the state of climate in the region and quantify variations in them. Hence, understanding historical trend of extreme precipitation events provide insightful to understanding change in regional climate dynamics across time and space. These understandings help governments to cope up with the hazards and adopt necessary strategies for sustainable water management.

A wide assortment of studies spanning across global, continental, regional and local scale have been conducted in past to understand the behavior of extreme events and their variability (Kim et al. 2019; Nguyen et al. 2018; Sheikh et al. 2015; Sun et al. 2021). However, the spatial and temporal variability of the precipitation and extreme events are not consistent across the world. Precipitation trend increased by 7 to $12 \%$ for areas between $30^{\circ}$ to $85{ }^{\circ} \mathrm{N}$ and by $2 \%$ in 
Southern Hemisphere between $0^{\circ}$ to $55^{\circ} \mathrm{S}$ (Xu et al. 2005). Similar trends for extreme events were observed in midlatitude regions of Northern Hemisphere on a global scale (Alexander et al. 2006). At continental scale, an increasing trend in precipitation was seen in North America, Argentina, and Australia during period of 1900 to 1988 (Dai et al. 1997). Remarkable increase in precipitation has been observed over the Europe (Schönwiese and Rapp 2013) whereas the extreme rainfall trend has reduced over southeast Asia, western and south Pacific over the period of 1965 to 1998 (Manton et al. 2001). Variability of precipitation in south and central Asia showed little change with positive and negative trend during 1961 to 2000 (Klein Tank et al. 2006).

However, the global scale or continental scale studies may not completely represent the regional or national scale trend. Though the annual precipitation has reduced slightly throughout China over the last five decades (Zhai et al. 1999), the heaviest precipitation has significantly risen over the Yangtze River and West China in the last decades of $20^{\text {th }}$ century (Zhai et al. 2005). Further, spatial distribution of interannual precipitation trends may be different with in a region compared to annual trend. Praveen et al. (2020) in their study revealed that northeastern, central and southern India detected negative trend for summer and monsoon seasons and insignificant trends for rest. While for winter season, northeastern, western and eastern part of India experienced positive trend and central part, southern and western Ghat exhibited declining trend. The precipitation has reduced in the winter and post-monsoon and has risen in monsoon and pre-monsoon on the China-Pakistan economic corridor over the period of 1980-2016 (Bhatti et al. 2020). In fact, mixed spatial trend pattern persists at sub boundaries level which when spatially aggregated to global or continental level could lead to averaged increasing or decreasing trend. That is, at larger scale opposite trends may nullify or small area with significant trends could dominate over larger area which otherwise may not exhibit any trends (Nguyen et al. 2018). In order to address these variabilities into national level planning, national and regional scale studies are required.

Afghanistan is a landlocked agrarian country by nature and about $79 \%$ of its population is engaged in farming though contribution to GDP from this sector is just $22 \%$ (Jawid and Khadjavi 2019). Political turmoil and decades of war have devastated country and resulted in more than $50 \%$ of poverty and $23 \%$ undernourished (The World Bank Group and The Asian Development Bank 2020). The country is prone to flood and drought hazards. More than 100,000 people are displaced every year due to flooding events (Ginnetti and Lavell 2015). Similarly, several incidences of drought cycles were recorded in past (1963-64; 1966-67;1970-72;1998-2006) affecting 9.8 million rural population leading to their displacement from west and northwest towards provincial centers (Přívara and Př́varová 2019). Despite minimal contribution to climate change, country is already experiencing climate induced hazards further exacerbated by low capacity to adapt (The World Bank Group and The Asian Development Bank 2020). In addition, farmers in least developed countries (like Afghanistan) are ravaged by extreme climatic events (Mendelsohn et al. 2006). Prolonged drought, exposed soil with minimal vegetation cover and reduced water draining capacity have increased the vulnerability of the land to respond to these extreme events. Precipitation is highly variable in Afghanistan owing to its complex topography and climatic characteristics. Increase in extreme events is likely to aggravate situation in the future. Therefore, it is important to assess long term trends and variability in precipitation and its extremes for appraisal of water resources among different sectors (Meshram et al. 2018). To statistically signify the rate of change with certain level of confidence, use of appropriate statistical technique has always been put forward by the scientific community. Several trend analysis methods are available however two methods are most widely used: parametric test (Malik and Kumar 2020) and non-parametric tests (Aawar et al. 2019; Cannarozzo et al. 2006; Sediqi et al. 2019; Nashwan et al. 2019).

However, one of the main challenges in analyzing precipitation trend in Afghanistan is the availability of long term observed climate data. Trend analysis involves long term time series from a dense network of rain gauge stations. In order to fill the gap, the use of gridded precipitation data along with the station data are seeking wider attention (Aich et al. 2017; Nashwan et al. 2019; Saini et al. 2020) of researchers. Constrained to data availability, very few studies are available on climate variability analysis in Afghanistan. Those available are mostly focused on local or basin scale climate change analysis of glacier concentrated around Hindu-Kush region (Akhundzadah et al. 2020; Ososkova et al. 2000; Unger-Shayesteh et al. 2013) and few on precipitation trend analysis (Aawar et al. 2019). Studies at national scale are based on the use of gridded precipitation data and mostly focused on climate change analysis (Aich et al. 2017; Qutbudin et al. 2019; Stockholm Environment Institute 2009). Stockholm Environment Institute (SEI) used Coupled Model Intercomparison Project (CMIP3) of $2.5^{\circ}$ x $2.5^{\circ}$ to analyze the socio-economic impact of climate 
change for Afghanistan. The study revealed the decrease in spring precipitation by $6.6 \%$ per decade (1960-2003). Likewise, Aich et al. (2017) studied the impact of climate change along with the two extreme indices for rainfall (heavy precipitation and spring precipitation) and three indices for droughts using reanalysis data of $0.5^{\circ} \mathrm{x} 0.5^{\circ}$ spatial resolution. The study found that the trend in annual precipitation was less distinct with -10 to $10 \%$ change for most parts and only small clusters in west and north experienced decrease up to $-20 \%$ for the period of 1951 to 2010 . Further, the study also indicated increase in heavy precipitation concentrated around the eastern region along the border of Pakistan. On the other hand, declining trends were observed in northern, western, and central highlands. Similarly, Qutbudin et al. (2019) studied the meteorological droughts during the wheat and rice cropping season using gridded data of $0.5^{\circ} \times 0.5^{\circ}$ spatial resolution. The study highlighted declining (inclining) trend of precipitation in southwestern (northeastern) during the winter and spring, wheat growing seasons for the historical climate analysis between 1951 to 2010. The same study observed the increasing (decreasing) trend of precipitation for eastern and southern (southwestern) during rice growing seasons - summer and autumn. Most of the results from later studies were consistent with the former studies in terms trends but different in terms of quantities. Also trend for spring precipitation was reported different by Qutbudin et al. (2019).

Based on the discussion, all the former studies were limited to either the average climate variability and future climate projections or heavy precipitation and drought analysis using coarser resolution reanalyzed data. Aich et al. (2017) highlighted the limitation of the coarser resolution data to represent the climate of highly varying topography of Afghanistan. Further, the climate extremes have profound impact compared to climatic mean. Thus, the main objective of this study is to analyze the trend in average precipitation as well as nine extreme indices proposed by Experts Team on Climate Change Detection Indices (ETCCDI) of the World Meteorological Organization (WMO) (Bhatti et al. 2020; Iqbal et al. 2019; Xuebin Zhang 2011; Zhang et al. 2011) using non-parametric Modified Mann-Kendall test (Hamed and Ramachandra Rao 1998) and Sen's slope (Sen 1968) estimator for the quantification of the trend. In order to achieve the objective, this study evaluates publicly available and differently scaled gauge based interpolated gridded precipitation dataset at daily scale: Asian Precipitation Highly Resolved Observational Data Integration Towards Evaluation (APHRODITE) and Climate Prediction Center (CPC). Gridded datasets are evaluated against the available gauge-based dataset using continuous statistical measures (bias, correlation coefficient, root-mean-squared-error and standard deviations) and better performing dataset is considered for further analysis.

\section{Materials and Methods}

\section{Study Area}

Afghanistan is a vast country with $652000 \mathrm{~km}^{2}$ area and estimated population of 34 million with $70 \%$ residing in rural areas (Sediqi et al. 2019). It is geographically located approximately between $29^{\circ}$ to $38^{\circ} \mathrm{N}$ latitude and $61^{\circ}$ to $74^{\circ} \mathrm{E}$ longitude in central zone of Asia and a part of the country lies within the Hindu-Kush Himalayan region. The country is bordered by Iran in west, Uzbekistan, Tajikistan and Turkmenistan in the north, Pakistan to the southeast and China in the northeast. The elevation of the country ranges between 230 to $7471 \mathrm{~m}$ above msl with highly undulating topography as presented in Fig.1. The country's area is dominated by mountains especially in north, northeast and east while relatively flat and deserted areas in southwest. Seven agro-climatic regions (Li-Ge et al. 2013) adopted by (Ministry of Agriculture Irrigation and Livestock 2017) in its 'Climate Change Scenarios for Agriculture of Afghanistan project' is adopted in this study for the regional analysis. The provinces under each ACR are given in Table 1.

Significant proportions of Afghani population, 79\% are engaged in agriculture (Jawid and Khadjavi 2019; Qutbudin et al. 2019) and the agriculture system is largely rain-water fed especially in rural Afghanistan. Different conditions for agriculture and livelihood persist due to its topographic heterogeneity. Large contiguous agricultural fields rarely exist in Afghanistan rather prevails in scattered strips along the valleys. Relatively contiguous areas and extensive farming can only be seen in northern foothills and Turkistan Plains where fairly flat terrain prevails (MAAH and FAO 2003). Northern and northeastern ACRs covers more than 55\% of arable land in the country also known as food basket of Afghanistan. Cropping is mainly done during summer, spring, and winter season. The main summer crops are rice and corn, and the main winter crops are barley and wheat. Wheat covers a major share, about $79 \%$ of the total cultivated area followed by rice $6.2 \%$ and corn $4.3 \%$. Winter crops are usually sown between mid of October to mid of 
December and harvested between mid of May to mid of July considering longer winters. Similarly, Summer crops are usually sown between end of March to end of June for corn and starting of June to mid of July for rice and harvesting is done between mid of August to end of October (Qutbudin et al. 2019). Wheat cultivation is done throughout the country while corn and water intensive rice are mainly cultivated in northern part of country owing to its water availability.

Table 1 Agro-climatic regions of Afghanistan (MAAH and FAO 2003)

\begin{tabular}{|l|l|l|}
\hline Agro-climatic zones & Provinces & Total arable land (ha/\%) \\
\hline Central & Kabul, Kapisa, Parwan, Panjshir, Bamyan, Ghazni and Wardak & $265,205(3.36 \%)$ \\
\hline Eastern & Kunar, Laghman, Nangarhar, Nuristan & $154,496(2.0 \%)$ \\
\hline Northern & Balkh, Faryab, Jawzjan, Samangan and Sar-e-pul & $2,683,606(34.7 \%)$ \\
\hline Northeast & Takhar, Baghlan, Badakhsan, Kunduz & $1,644,215(21.24 \%$ \\
\hline Southern & Khost, Logar, Paktika, Paktia & $487,726(6.21 \%)$ \\
\hline Southwest & Daykundi, Helmand, Kandahar, Urozgan, Zabul & $951,242(12.30 \%)$ \\
\hline Western & Nimroz, Baghis, Farah, Ghor, Herat & $1,311,017(16.96 \%)$ \\
\hline West-Central & Ghor, Bamyan & $258,314(3.23 \%)$ \\
\hline
\end{tabular}

Afghanistan has predominantly dry continental climate with hot and sunny summers and cold and rainy winter. It is characterized by little to no precipitation. However, considering the undulating topography of the nation, climate varies greatly between these topographic regions. Afghanistan generally observes four seasons. Winter commences in the month of December and ends by the end of February (herein after DJF). March, April, and May are observed as spring season (MAM). Similarly, June, July, and August are observed as Summer (JJA) and September, October, and November as Autumn (SON). Winter and spring seasons are usually wet, and summer and autumn are dry in Afghanistan except for eastern region which is influenced by the summer monsoon. The winter monsoon is influenced by the large-scale humidity from the Caspian and the Black sea approaching from the northeastern, northern, and western ACRs. Similarly, the summer monsoon approaching from the Bay of Bengal, Indian Ocean and Arabian sea crossing India and Pakistan is only observed in the eastern, southern, and central ACRs with heavy rainfall (Shokory et al. 2017). The precipitation falls as snow in high mountains during winter and spring seasons that act as water towers and source of water in rivers during summer. 

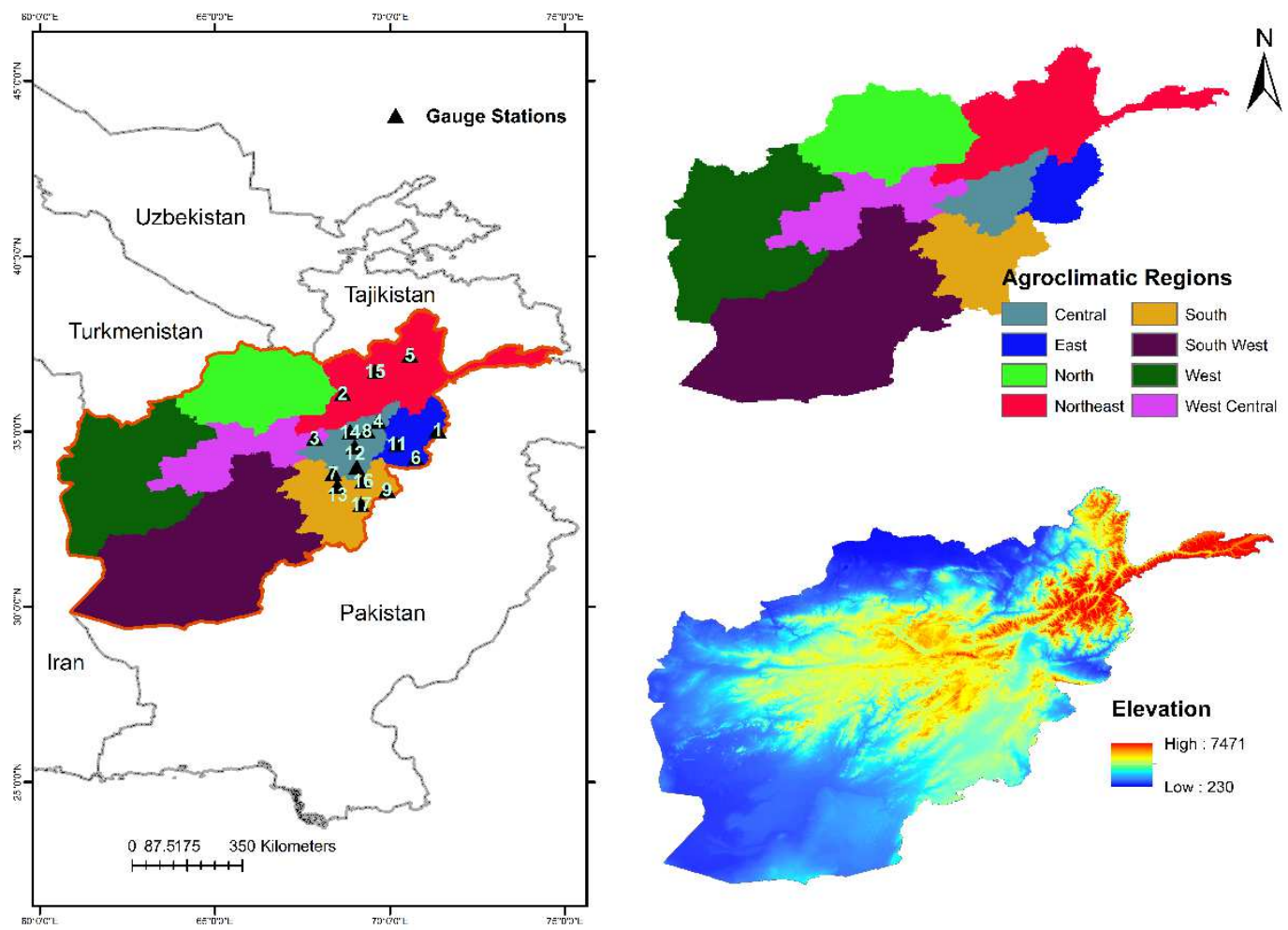

Fig. 1 Map of Afghanistan along with gauge stations, agro climatic regions and elevation profile

The spatial distribution of rainfall is heterogeneous throughout the country. The northeastern, eastern, central, and southern ACRs receives higher rainfall compared to the scanty rainfall in southwestern, western, and northern regions. The average annual, seasonal, and monthly rainfall of the country is presented in Fig. 2 and Fig. 3 based on Asian Precipitation Highly Resolved Observational Data Integration Towards Evaluation (APHRODITE) considering the confinement of provided observed gauge data into certain ACRs only as presented in Fig. 1. The name, latitude and longitude of stations are provided in Table 5. The choice and evaluation of gridded products is provided in subsequent sections. The average annual precipitation ranges from $<60 \mathrm{~mm}$ in the southwestern ACR to $>840 \mathrm{~mm}$ in the eastern ACR. Seasonal precipitation changes between $<39.47 \mathrm{~mm}$ (southwest end) to $>350 \mathrm{~mm}$ in eastern ACR in winter and spring seasons. It is remarkably below $10 \mathrm{~mm}$ in summer and autumn for majority of ACRs (TÜNNERMEIER and HOUBEN 2005). The southwest monsoon usually extends two seasons, winter, and spring for all ACRs. In addition,
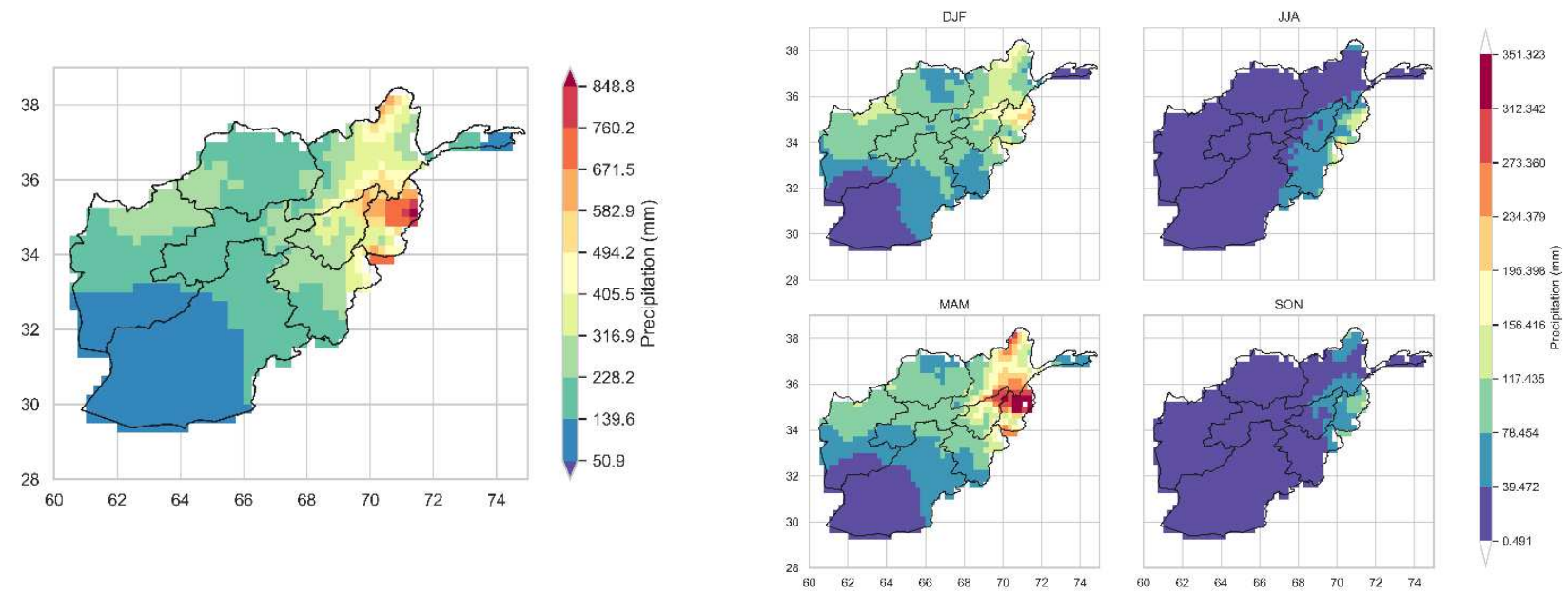

Fig. 2 Average annual (left) and seasonal precipitation (right) distribution across Afghanistan 
the eastern, southern and central ACRs receives precipitation during summer season as a part of Asian Summer Monsoon (Aich et al. 2017).

The temperature in summer is approximately $33^{\circ} \mathrm{C}$ and $10^{\circ} \mathrm{C}$ in winter, but in cold areas temperature could fall below $-20^{\circ} \mathrm{C}$ (McSweeney et al. 2010).
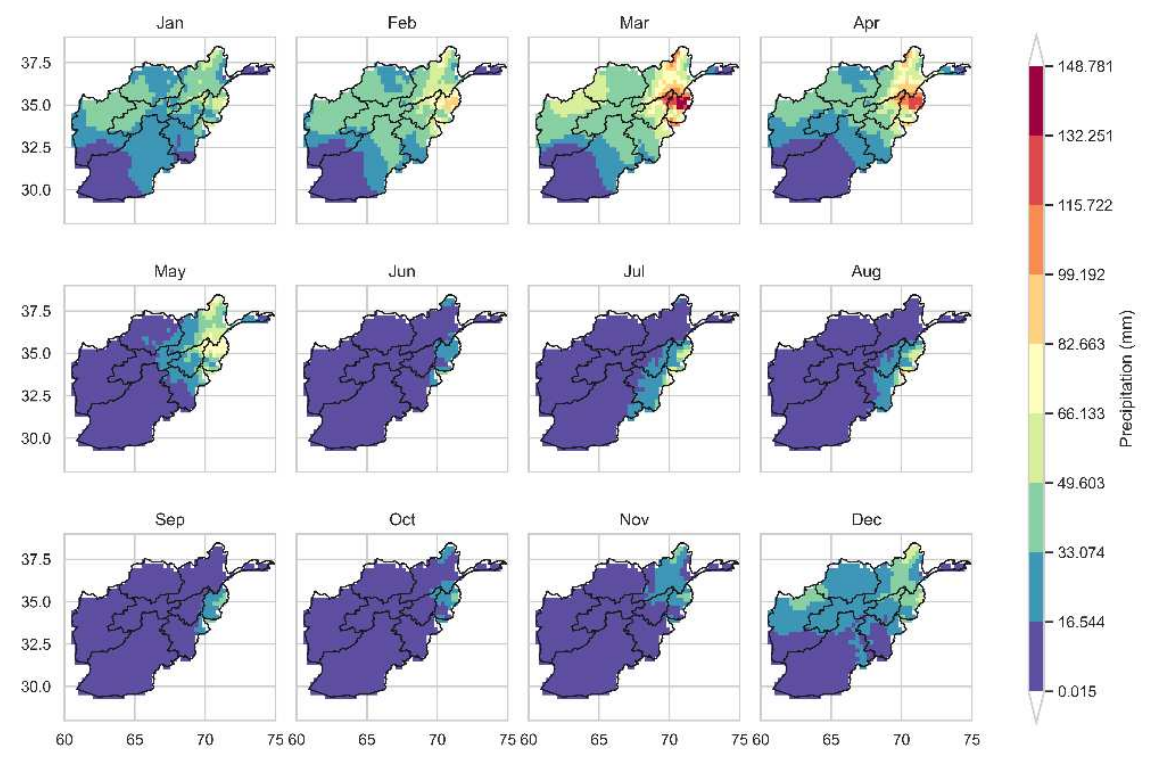

Fig. 3 Spatial distribution of average monthly precipitation across Afghanistan

\section{Observed station data}

One main challenge in climate analysis in Afghanistan is the availability of the long-term and reliable observed climatic data. Observed long term time series in Afghanistan is scarce because of scattered meteorological stations, political instability and destruction of records and stoppage of observation during Taliban regime (Aich et al. 2017). The insitu daily precipitation gauge data from 17 meteorological stations were made available by Islamic Republic of Afghanistan Civil Aviation Authority Meteorological Department for the period of 2006 to 2011. The provided data are mostly concentrated around the central, eastern, northeastern and southern ACR. Considering the short-term availability of the observed dataset, gauge based interpolated gridded datasets were considered for long term trend analysis.

\section{Gridded Dataset}

In order to overcome the shortcomings of the observed dataset for trend analysis, gauge based interpolated gridded daily precipitation datasets: APHRODITE and Climate Prediction Center (CPC) were used for this study. Summary of the dataset along with their spatial and temporal resolution and sources are presented in Table2.

\section{APHRODITE}

APHRODITE datasets are the quality controlled interpolated continental-scale daily precipitation product at the spatial resolution of $0.25^{\circ} \times 0.25^{\circ}$ for the period of 1951 to 2010 (61 years) collected from in-situ rain gauge observation network ranging between 5000 to 12000 stations including Global Telecommunication Systems (GTS) and compiled products of several national and international institutes (Kim et al. 2019). Daily precipitation data were spatially 
averaged and extracted for each ACR for further regional analysis. The daily precipitation data were further processed to obtain monthly, annual and seasonal timeseries.

\section{CPC}

The CPC is a gauge-based interpolated daily precipitation dataset of National Oceanic and Atmospheric Administration (NOAA). It is a quality controlled daily precipitation product with improved quantitative accuracy and inter-products consistency developed based on the gauge reports from over 30,000 stations including GTS, Cooperative Observer Network (COOP), and several national and international institutes. The dataset is available at $0.5^{\circ} \times 0.5^{\circ}$ spatial resolution starting form 1979 onwards (Xie et al. 2007). Table 2 presents summary of the gridded dataset used in the study.

Table 2 Gridded datasets, their spatial and temporal resolution and sources

\begin{tabular}{|c|c|c|c|c|}
\hline Dataset & $\begin{array}{l}\text { Spatial } \\
\text { Resolution }\end{array}$ & $\begin{array}{l}\text { Temporal } \\
\text { Resolution }\end{array}$ & $\begin{array}{l}\text { Available } \\
\text { Time Span }\end{array}$ & Data sources \\
\hline $\begin{array}{l}\text { APHRO } \\
\text { DITE }\end{array}$ & $0.25^{\circ} \times 0.25^{\circ}$ & Daily & $\begin{array}{l}1951 \text { to } \\
2015\end{array}$ & $\begin{array}{l}\text { (Yatagai et al. 2012; Lauri et al. 2014; Rai et al. 2015) } \\
\text { http://APHRODITE.st.hirosaki-u.ac.jp/download// } \\
\text { (Accessed on } 30 \text { Dec } 2020)\end{array}$ \\
\hline $\mathrm{CPC}$ & $0.5^{\circ} \times 0.5^{\circ}$ & Daily & $1979-2019$ & $\begin{array}{l}\text { (Xie et al. 2007) } \\
\text { https://www.esrl.noaa.gov/psd/data/gridded/Tables/precipi } \\
\text { tation.html (Accessed on 30 Dec 2020) }\end{array}$ \\
\hline
\end{tabular}

\section{Methods}

\section{Evaluation of Gridded Datasets}

Table 3 houses four continuous statistical measures, correlation coefficient (r), bias (B), standard deviation (SD) and root mean square error (RMSE) used to quantify the errors and evaluate the performance of the gridded datasets. These statistical metrics are chosen because they have been widely used to evaluate the performance of satellite-based rainfall products using ground observation as reference data and are found to provide a consistent and trustful products' evaluation (Deng et al. 2018; Ghulami et al. 2017; Nkunzimana et al. 2020; Yeggina et al. 2020). The evaluation is carried out between the period of 2006 to 2011 on the monthly time scale overlapping with time period of observed data. In order to capture the differences in spatial performance, these indices were calculated separately for each station under study. Correlation coefficient measures the linear consistency between gridded and observed dataset. The $r$ value close to 1 indicate good performance and 0 indicate no relation at all. Similarly, RMSE is the measure of differences (error) between the observed and gridded dataset. The value of RMSE close to 0 indicate better performance. The bias is the difference between observed and gridded dataset. Positive value indicate magnitude of overestimation of precipitation by gridded product and negative value indicates the underestimation. Likewise, SD is the measure of amount of variation or spread in the dataset. Higher value indicates data is wide spread from the mean and lower value indicates the data is concentrated around the mean value.

Table 3 Continuous statistical measures for evaluation of performance of gridded dataset against observed dataset

\begin{tabular}{|l|r|l|}
\hline Error Measure & Equation & Unit \\
\hline Bias & $\mathrm{B}=\sum_{\mathrm{i}=1}^{\mathrm{n}}\left(\mathrm{Y}_{\mathrm{i}}-\mathrm{O}_{\mathrm{i}}\right)$ & $\mathrm{mm}$ \\
\hline Root mean square error & $\mathrm{RMSE}=\sqrt{\frac{1}{\mathrm{n}}\left(\sum_{\mathrm{i}=1}^{\mathrm{n}}\left(\mathrm{Y}_{\mathrm{i}}-\mathrm{O}_{\mathrm{i}}\right)\right)^{2}}$ & $\mathrm{~mm}$ \\
\hline
\end{tabular}




\begin{tabular}{|l|c|l|}
\hline $\begin{array}{l}\text { Correlation coefficient } \\
(\mathrm{r})\end{array}$ & $\mathrm{r}=\frac{\sum_{\mathrm{i}=1}^{\mathrm{n}}\left(\mathrm{Y}_{\mathrm{i}}-\overline{\mathrm{Y}}\right)\left(\mathrm{O}_{\mathrm{i}}-\overline{\mathrm{O}}\right)}{\sqrt{\sum_{\mathrm{i}=1}^{\mathrm{n}}\left(\mathrm{Y}_{\mathrm{i}}-\overline{\mathrm{Y}}\right)^{2} \sqrt{\sum_{\mathrm{i}=1}^{\mathrm{n}}\left(\mathrm{O}_{\mathrm{i}}-\overline{\mathrm{O}}\right)^{2}}}}$ & \\
\hline Standard Deviation & $\mathrm{SD}=\sqrt{\frac{\sum\left(\mathrm{Y}_{\mathrm{i}}-\overline{\mathrm{Y}}\right)^{2}}{\mathrm{n}}}$ & $\mathrm{mm}$ \\
\hline
\end{tabular}

$\mathrm{O}, \mathrm{Y}$ are the observed precipitation and estimated gridded respectively

$\overline{\mathrm{O}}, \overline{\mathrm{Y}}$ are mean observed precipitation and average estimated gridded precipitation respectively $\mathrm{n}$ is the number of data points

\section{Statistical Analysis}

Several data analysis techniques are in practice for rainfall under variability and trend analysis. Variability involves the use of Coefficient of Variation (CV), percentage of departure from the mean (Anomalies), Precipitation Concentration Index (PCI) and moving average. Likewise, Skewness and Kurtosis describes the distribution of data. Skewness, a dimensionless parameter, is a measure of asymmetry of a probability distribution i.e., negative value of Skewness indicates that the left tail is larger than the right tail of a probability distribution curve and vice versa. Similarly, Kurtosis characterizes the relative peakedness or flatness of a probability distribution curve compared to a normal distribution. Positive value of Kurtosis indicates the peakedness in data while negative value indicates flatness of the distribution. The CV, Skewness, and Kurtosis are used to describe the precipitation statistics for monthly, seasonal and annual timeseries (Li-Ge et al. 2013; Saini et al. 2020). Higher the CV higher is the variability in temporal distribution and lower the value more sTable is the time series. Similarly, trend detection involves the parametric and non-parametric tests. Data should be continuous, normally distributed, independent and have identical distribution in parametric test while only condition to be met for non-parametric test is data should be independent (free from serial correlation).

\section{Extreme Precipitation Indices (EPIs)}

This study used nine precipitation indices suggested by the Experts Team on Climate Change Detection Indices (ETCCDI) of the World Meteorological Organization (WMO) to study extreme indices events (Bhatti et al. 2020; Ongoma et al. 2018; Xuebin Zhang 2011). These nine indices can be put into 3 categories (Zhang and Liang 2020; Zhou et al. 2018) namely, frequency indices, duration indices and intensity indices. The description of the indices is presented in the Table 4.

Table 4 ETCCDI extreme indices for precipitation

\begin{tabular}{|c|c|c|c|c|}
\hline Category & Index & Descriptive name & Definition & Units \\
\hline \multirow[t]{2}{*}{$\begin{array}{l}\text { Duration } \\
\text { Indices }\end{array}$} & CDD & $\begin{array}{ll}\begin{array}{l}\text { Consecutive dry } \\
\text { days }\end{array} & \\
\end{array}$ & $\begin{array}{l}\text { Maximum number of consecutive dry days } \\
\text { (precipitation }<1 \mathrm{~mm} \text { ) }\end{array}$ & days \\
\hline & CWD & $\begin{array}{l}\text { Consecutive wet } \\
\text { days }\end{array}$ & $\begin{array}{l}\text { Maximum number of consecutive wet days } \\
\text { (precipitation }>1 \mathrm{~mm})\end{array}$ & days \\
\hline \multirow[t]{4}{*}{$\begin{array}{l}\text { Frequency } \\
\text { Indices }\end{array}$} & $\mathrm{R} 10 \mathrm{~mm}$ & $\begin{array}{l}\text { Heavy precipitation } \\
\text { days }\end{array}$ & $\begin{array}{l}\text { Annual count of days when daily rainfall rate (RR) } \\
\geq 10\end{array}$ & days \\
\hline & $\mathrm{R} 20 \mathrm{~mm}$ & $\begin{array}{l}\text { Very heavy } \\
\text { precipitation days }\end{array}$ & Annual count of days when $R R \geq 20$ & days \\
\hline & R95p & $\begin{array}{l}\text { Very wet } \\
\text { precipitation }\end{array}$ & $\begin{array}{l}\text { Number of days when annual total precipitation } \\
\text { when RR }>95^{\text {th }} \text { percentile of } 1951-2007 \text { daily } \\
\text { rainfall }\end{array}$ & days \\
\hline & R99p & $\begin{array}{l}\text { Extremely wet day } \\
\text { precipitation }\end{array}$ & $\begin{array}{l}\text { Number of days when annual total precipitation } \\
\text { when RR }>99^{\text {th }} \text { percentile of } 1951-2007 \text { daily } \\
\text { rainfall }\end{array}$ & days \\
\hline $\begin{array}{l}\text { Intensity } \\
\text { Indices }\end{array}$ & PRCPTOT & $\begin{array}{l}\text { Wet } \\
\text { precipitation }\end{array}$ & Annual total precipitation from wet days & $\mathrm{mm}$ \\
\hline
\end{tabular}




\begin{tabular}{|l|l|l|l|l|l|}
\hline & RX1day & $\begin{array}{l}\text { Maximum 1-day } \\
\text { precipitation }\end{array}$ & Annual maximum 1-day precipitation & $\mathrm{mm}$ \\
\cline { 2 - 4 } RX5day & $\begin{array}{l}\text { Maximum } \\
\text { precipitation }\end{array}$ & Annual maximum consecutive 5-day precipitation & $\mathrm{mm}$ \\
\hline
\end{tabular}

The EPIs for the entire nation were calculated using Xclim package for python for daily precipitation NetCDF file. Indices were calculated at annual scale. The trends in EPIs were assessed using Modified test and the significance of the trend was obtained using Sen's slope estimator at the significance level of $5 \%$.

\section{Normality Test}

Prior to application of trend analysis, monthly, seasonal, and annual timeseries were tested for normality for each ACR. Both graphical and statistical methods are available for the normality test. This study utilized two normality tests namely, Saphiro-Wilk (SW) test and Anderson-Darling (AD) Test. SW test followed by AD test have proved their powerfulness in determining the normality of the timeseries dataset(Aamir and Hassan 2018; Mendes and Pala 2003).

\section{Saphiro-Wilk Test}

Shapiro and Wilk (1965) test was initially limited to the sample size of 50. Royston (1982) later developed algorithm to generate approximation and Tabled values for the coefficients (Mendes and Pala 2003). It has been widely used owing to its good power properties (Mendes and Pala 2003; Razali and Wah 2010). For a given ordered random sample of $\mathrm{y}_{1}, \mathrm{y}_{2}, \mathrm{y}_{3}, \ldots . ., \mathrm{y}_{\mathrm{n}}$, the $\mathrm{SW}$ test statistic is defined as,

$$
\mathrm{W}=\frac{\left(\sum_{\mathrm{i}=1}^{\mathrm{n}} \mathrm{a}_{\mathrm{i}} \mathrm{y}_{\mathrm{i}}\right)^{2}}{\left(\sum_{\mathrm{i}=1}^{\mathrm{n}}\left(\mathrm{y}_{\mathrm{i}}-\overline{\mathrm{y}}\right)^{2}\right.}
$$

Where $y_{i}$ is the $i^{\text {th }}$ order statistic,

$\overline{\mathrm{y}}$ is the sample mean,

$a_{i}=\left(a_{1}, a_{2}, \ldots, a_{n}\right)=\frac{m^{T} V^{-1}}{\left(\left\{(m\}^{T} V^{-1} m\right)^{1 / 2}\right.}$

$\mathrm{m}=\left(\mathrm{m}_{1}, \mathrm{~m}_{2}, \ldots, \mathrm{m}_{\mathrm{n}}\right)^{\mathrm{T}}$ are values of order statistics of identically distributed and independent random variables sampled for the normal standard distribution and

$\mathrm{V}=$ covariance matrix of ordered statistics.

\section{Anderson-Darling Test}

Anderson and Darling (1954) normality test is defined as:

$$
\mathrm{W}_{\mathrm{n}}^{2}=\mathrm{n} \int_{-\infty}^{\infty}\left\{\left[\mathrm{F}_{\mathrm{n}}(\chi)-\mathrm{F}^{*}(\chi)\right]^{2} \psi\left(\mathrm{F}^{*}(\mathrm{X})\right\}\right) \mathrm{dF}^{*}(\chi)
$$

Where $\psi$ is a non -negative weight function calculated as

$$
\psi=\left[\mathrm{F}^{*}(\chi)\left(1-\mathrm{F}^{*}(\chi)\right)\right]^{-1}
$$

Both tests assume the null hypothesis that the time series comes from a normal distribution. The test statistics (W) is compared against a critical value of theoretical distribution. The null hypothesis is rejected if the test statistics is greater than the critical value and accepted otherwise. Both SW and AD tests were implemented using SciPy, an opensource software for mathematics, science and engineering, in python(version 3.8) environment (Javari 2016). A significance level (critical value) of 5\% (0.05) was considered for the evaluation of all ACRs.

\section{Modified Mann-Kendall Test}


The Mann-Kendall (Mann 1945), a statistical non-parametric test, is widely used in the trend analysis of hydroclimatic time series. The test was first devised by Henry B. Mann in 1945 and has been extensively used since then. The test assumes the absence of trend as a null hypothesis ( $\mathrm{H} 0)$ which is tested against the alternate hypothesis $(\mathrm{H} 1)$ that assumes presence of trend in the time series. For a time series data of $x 1, x 2, x 3 \ldots . . x n$ with $n \geq 8$, the M-K test statistic $(\mathrm{S})$ the variance $(\mathrm{V}(\mathrm{S}))$, and the associated standard normal test statistic $(\mathrm{Z})$ are computed as follows:

$$
\begin{gathered}
S=\sum_{k=1}^{n-1} \sum_{j=k+1}^{n} \operatorname{sgn}\left(x_{j}-x_{k}\right) \\
Z=\frac{S-1}{\operatorname{sqrt}(V(S))} \quad \text { for } S>0 \\
z=\left(\begin{array}{cc}
\frac{s-1}{\sqrt{V(S)}} & \text { for } S>0 \\
0 & \text { for } S=0 \\
\frac{S+1}{\sqrt{V(S)}} & \text { for } S<0
\end{array}\right) \\
\operatorname{sgn}\left(x_{j}-x_{i}\right)=\left(\begin{array}{cc}
1 & \text { for }\left(x_{j}-x_{i}\right)>0 \\
0 & \text { for }\left(x_{j}-x_{i}\right)=0 \\
-1 & \text { for }\left(x_{j}-x_{i}\right)<0
\end{array}\right) \\
\operatorname{Var}(S)=\frac{n(n-1)(2 n+5) \sum_{p-1}^{q} t_{p}-\left(t_{p}-1\right)\left(2 t_{p}+5\right)}{18}
\end{gathered}
$$

Where q represents total number of tied groups. Tied groups are the set of same values in dataset and each tied group is represented by $t_{p}$. The positive values of $Z$ indicate the increasing trends in timeseries while negative values represent decreasing trends and 0 represents no trend at all.

The presence of serial autocorrelation (correlation between $n$ and $n-k$ time series, where $k$ is the lag) in the time series would sometimes mislead the trend results i.e., increase in the chances in rejecting null hypothesis of no trend (Piyoosh and Ghosh 2017). To overcome this issue, Modified Mann-Kendall Test (MMKT) devised by Hamed and Ramachandra Rao (1998) is used in this study (Hamed and Ramachandra Rao 1998; Saini et al. 2020). The MMKT follows similar approach to Mann-Kendall test with variance correction in addition. The MMKT does not require data to be free of serial correlation. The variance correction approach in MMKT assumes that $\mathrm{N}$ serially correlated dataset gives the same information as $\mathrm{M}(\mathrm{M}<\mathrm{N})$ uncorrelated variables however serial correlation changes the variance of the dataset.

Variance correction,

$$
\begin{gathered}
\mathrm{V}(\mathrm{S})^{*}=\mathrm{cf} * \mathrm{~V}(\mathrm{~S}) \\
\left.\mathrm{cf}=1+\frac{2}{\mathrm{~N}}(\mathrm{~N}-1)(\mathrm{N}-2)\right\} \sum_{\mathrm{k}=1}^{\mathrm{N}-1} \mathrm{~N}(\mathrm{~N}-\mathrm{k})(\mathrm{N}-\mathrm{k}-1)(\mathrm{N}-\mathrm{k}-2) \mathrm{r}_{\mathrm{k}}^{\mathrm{R}}
\end{gathered}
$$

$\mathrm{V}(\mathrm{S})^{*}$ is the corrected variance obtained after correction and cf represents the correction factor proposed by Rao et al.(Saini et al. 2020).

The statistical significance of the computed tests is then compared against the critical values $\left(\mathrm{Z}_{1-\mathrm{a}}\right)$ where 1-a is the confidence level.

\section{Sen's Slope Estimator}


The MK/ MMK tests indicate the presence of trend and Sen's slope, also a non-parametric test, quantifies the magnitude of detected trends in the time series (Sen 1968). Sen's slope method is widely used and is robust against outlier. The Sen's slope (SS) is calculated as below:

$$
\text { SS }=\operatorname{median}\left(\frac{x_{j}-x_{i}}{j-i}\right) \text { for all } i<j
$$

where $\mathrm{x}_{\mathrm{i}}, \mathrm{x}_{\mathrm{j}}$ are the values of the data in time step $\mathrm{i}$ and $\mathrm{j}$ respectively.

The pyMannKendall (Hussain and Mahumud 2019) package was employed to calculate test statistics for MMK test and Sen's Slope in python 3.8 environment.

\section{Results}

\section{Evaluation of gridded datasets}

Results for different performance measures of APHRODITE and CPC for seventeen stations are presented in Table 5. During the period of 2006-2011, APHRODITE product outperforms CPC dataset for about $70 \%$ of stations in terms of bias, RMSE and correlation coefficient. Ten of seventeen stations indicated high correlation coefficient $(>0.7)$ for APHRODITE compared to just four stations for CPC. Further, the continuous statistical performance indicators for each station against APHRODITE and CPC is presented in Fig. 4 by Taylor diagram (Taylor 2001). Taylor diagram (Fig. 5) summarizes the performance based on three statistical metrics: i) standard deviations, ii) Pearson's correlation coefficient, ii) centered root-mean-squared differences. Comparatively, better performance of APHRODITE can be attributed to pivotal role of gauge-based dataset ( $\mathrm{Li}$ et al. 2013; Merino et al. 2021) and its spatial resolution. Furthermore, the selection was also guided by the performance outlined in existing literature (Ghulami et al. 2017; Lauri et al. 2014; Rai et al. 2015; Yang et al. 2017). APHRODITE precipitation product has better performance in the Asian region in both flat plain (Lauri et al. 2014; Rai et al. 2015) and arid and semi-arid region(Yang et al. 2017). Henceforth, all the analysis of the precipitation and its extreme indices for whole Afghanistan is carried out only for APHRODITE dataset.

Table 5 Comparison of biases, RMSE and correlation coefficients for the monthly precipitation between observed station and APHRODITE and CPC

\begin{tabular}{|c|c|c|c|c|c|c|c|c|c|c|}
\hline & & & $\mathbf{B i}$ & & $\mathbf{R M}$ & & SI & & $\mathbf{r}$ & \\
\hline Stations & $\begin{array}{l}\text { Latit } \\
\text { ude }\end{array}$ & $\begin{array}{c}\text { Longit } \\
\text { ude }\end{array}$ & $\begin{array}{l}\text { APHR } \\
\text { ODITE }\end{array}$ & CPC & $\begin{array}{l}\text { APHR } \\
\text { ODITE }\end{array}$ & CPC & $\begin{array}{l}\text { APHR } \\
\text { ODITE }\end{array}$ & CPC & $\begin{array}{c}\text { APHR } \\
\text { ODITE }\end{array}$ & CPC \\
\hline Asmar & 35.04 & 71.36 & 1.01 & -10.72 & 47.91 & 49.70 & 54.35 & 54.54 & 0.70 & 0.69 \\
\hline Baghlan & 36.09 & 68.65 & 4.63 & -3.72 & 18.09 & 14.29 & 21.42 & 22.99 & 0.72 & 0.84 \\
\hline Bamyan & 34.82 & 67.85 & 11.92 & 14.75 & 21.54 & 25.08 & 21.42 & 27.66 & 0.66 & 0.69 \\
\hline $\begin{array}{l}\text { Dara } \\
\text { Panjsheer }\end{array}$ & 35.29 & 69.66 & -7.60 & -26.90 & 58.24 & 74.14 & 50.35 & 30.76 & 0.74 & 0.62 \\
\hline Fayzabad & 37.19 & 70.57 & -12.22 & -21.58 & 39.73 & 38.38 & 28.03 & 25.76 & 0.58 & 0.75 \\
\hline $\begin{array}{l}\text { Ghazi } \\
\text { Abad }\end{array}$ & 34.26 & 70.74 & 13.46 & 28.94 & 25.82 & 44.81 & 28.42 & 42.35 & 0.69 & 0.59 \\
\hline Jaghatoo & 33.82 & 68.38 & -45.33 & -33.33 & 100.08 & 95.25 & 23.14 & 35.35 & 0.79 & 0.56 \\
\hline Kapisa & 35.03 & 69.35 & 5.33 & -0.56 & 2S9.15 & 34.27 & 36.45 & 27.77 & 0.80 & 0.70 \\
\hline Khost & 33.34 & 69.92 & 2.20 & 6.41 & 37.73 & 39.71 & 39.65 & 47.68 & 0.62 & 0.65 \\
\hline Logar & 33.99 & 69.05 & 11.86 & 26.09 & 19.23 & 41.35 & 26.31 & 41.22 & 0.83 & 0.63 \\
\hline Mehtarlam & 34.65 & 70.20 & 14.31 & 23.15 & 27.37 & 36.41 & 32.27 & 36.06 & 0.69 & 0.63 \\
\hline Paghman & 34.58 & 68.99 & -16.47 & -14.35 & 58.50 & 67.15 & 34.79 & 34.94 & 0.77 & 0.56 \\
\hline Sarday & 33.46 & 68.50 & 14.04 & 27.20 & 21.96 & 43.36 & 20.21 & 37.64 & 0.58 & 0.44 \\
\hline Seya Gerd & 35.00 & 68.86 & 22.83 & 23.69 & 35.34 & 40.59 & 36.76 & 36.22 & 0.69 & 0.52 \\
\hline
\end{tabular}




\begin{tabular}{|l|r|r|r|r|r|r|r|r|r|r|} 
Taluqan & 36.72 & 69.57 & 2.12 & -10.17 & 29.89 & 25.05 & 31.60 & 29.81 & 0.65 & 0.80 \\
\hline $\begin{array}{l}\text { Tera } \\
\text { Forestry }\end{array}$ & 33.60 & 69.23 & -5.49 & 11.30 & 39.05 & 55.29 & 26.64 & 45.11 & 0.72 & 0.40 \\
\hline Urgon & 32.94 & 69.17 & -17.32 & -8.79 & 47.20 & 55.27 & 23.65 & 38.63 & 0.74 & 0.43 \\
\hline
\end{tabular}

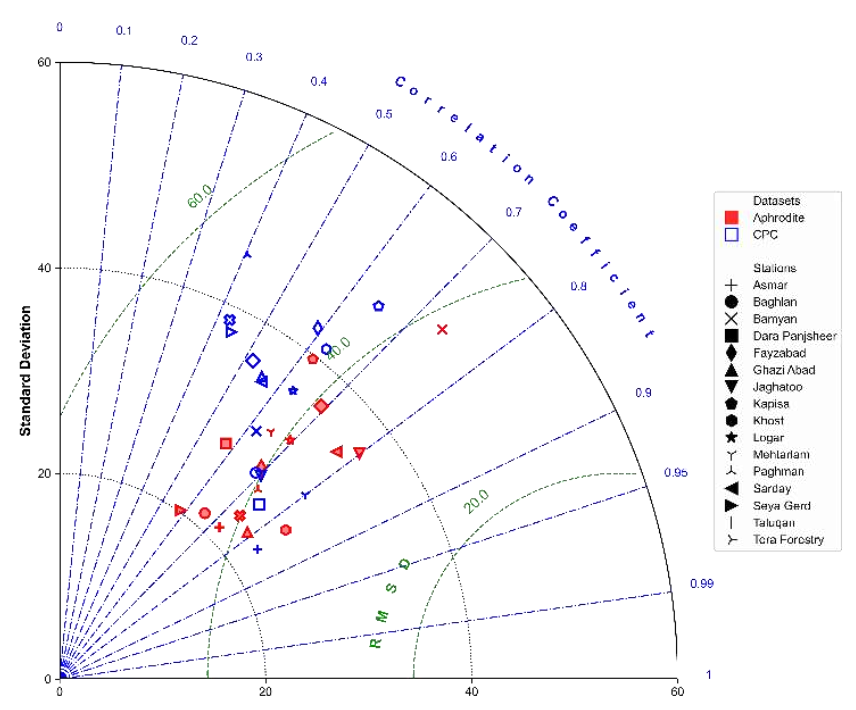

Fig. 4 Taylor Diagram displaying the evaluation of gridded dataset products against the observed dataset (a) blue and red color represent CPC and APHRODITE dataset respectively b) different symbols represents different stations

\section{Precipitation Statistics}

The statistics of spatially averaged precipitation for monthly, seasonal, and annual time series for entire Afghanistan is presented in Table 6. The mean annual precipitation during the study period in Afghanistan was $313.85 \mathrm{~mm}$ with the standard deviation of $89.38 \mathrm{~mm}$. The minimum and maximum values of precipitation were $157.47 \mathrm{~mm}$ and 559.29 $\mathrm{mm}$ respectively with $30.07 \%$ of CV. The Skewness and Kurtosis values of 0.5 and 0.11 indicated that the probability distribution of the annual rainfall was approximately symmetrical and normal. Winter (DJF) and spring (MAM) seasons (monsoon) observed the highest precipitation cumulatively accounting for more than $75 \%$ of the annual precipitation and least CV (38.12 to $39.14 \%$ ). Contrarily, cumulative summer (JJA) and autumn (SON) seasons (dry) precipitation contributed less than $25 \%$ of the total annual precipitation and more than $90 \%$ of CV indicating high variability and inconsistent precipitation during these seasons. Similarly, the lower (higher) values of Skewness and Kurtosis for spring and winter (summer and autumn) precipitation revealed relatively light (heavy) tailed and flat (peaked) precipitation. Precipitation during months of June, July, August, September, and November exhibited high skewness towards right and relatively peakedness compared to the monsoon months.

Table 6 Spatially averaged monthly, annual and seasonal precipitation statistics for Afghanistan

\begin{tabular}{|c|c|c|c|c|c|c|c|c|}
\hline $\begin{array}{c}\text { Months/ } \\
\text { Seasons }\end{array}$ & Minimum & Maximum & Mean & SD & Kurtosis & Skewness & CV & $\begin{array}{l}\text { Contribution } \\
\text { to Annual } \\
\text { Precipitation } \\
\text { (Piyoosh and } \\
\text { Ghosh 2017) }\end{array}$ \\
\hline Jan & 2.53 & 93.67 & 34.28 & 21.79 & -0.11 & 0.64 & 63.21 & $\mathbf{1 0 . 9 2}$ \\
\hline
\end{tabular}




\begin{tabular}{|c|c|c|c|c|c|c|c|c|}
\hline Feb & 4.56 & 112.47 & 45.21 & 23.97 & 0.05 & 0.62 & 52.81 & $\mathbf{1 4 . 4 0}$ \\
\hline Mar & 5.91 & 136.13 & 58.78 & 26.95 & 0.40 & 0.42 & 45.23 & $\mathbf{1 8 . 7 3}$ \\
\hline Apr & 6.16 & 137.89 & 48.13 & 26.57 & 1.26 & 0.94 & 59.15 & $\mathbf{1 5 . 3 4}$ \\
\hline May & 3.22 & 72.85 & 26.81 & 16.99 & 0.22 & 0.84 & 70.73 & $\mathbf{8 . 5 4}$ \\
\hline Jun & 1.09 & 33.38 & 9.16 & 7.15 & 3.98 & 1.89 & 105.39 & 2.92 \\
\hline Jul & 3.47 & 57.93 & 14.67 & 9.85 & $\mathbf{9 . 4 9}$ & 2.37 & 116.33 & 4.67 \\
\hline Aug & 3.24 & 56.57 & 15.12 & 9.62 & 7.08 & 2.11 & 120.11 & 4.82 \\
\hline Sep & 0.86 & 42.74 & 10.25 & 8.32 & 7.96 & $\mathbf{2 . 4 2}$ & $\mathbf{1 2 8 . 7 8}$ & 3.27 \\
\hline Oct & 0.27 & 56.56 & 10.35 & 10.84 & 6.38 & 2.25 & 114.14 & 3.30 \\
\hline Nov & $\mathbf{0 . 2 0}$ & 59.55 & 15.39 & 13.47 & 1.87 & 1.34 & 89.89 & 4.91 \\
\hline Dec & 0.55 & 91.45 & 25.70 & 19.09 & 2.04 & 1.22 & 73.51 & $\mathbf{8 . 1 9}$ \\
\hline Winter & 30.29 & 202.66 & 105.19 & 39.99 & $\mathbf{- 0 . 4 4}$ & $\mathbf{0 . 3 3}$ & 38.12 & 33.52 \\
\hline Spring & 38.80 & 270.10 & 133.72 & 49.78 & 0.00 & 0.40 & 39.14 & 42.61 \\
\hline Summer & 10.26 & 140.98 & 38.95 & 22.07 & 8.84 & 2.33 & 97.05 & 12.41 \\
\hline Autumn & 7.30 & 121.24 & 36.00 & 22.03 & 5.10 & 1.59 & 70.14 & 11.47 \\
\hline Annual & 151.47 & $\mathbf{5 5 5 . 2 9}$ & $\mathbf{3 1 3 . 8 5}$ & $\mathbf{8 9 . 3 8}$ & 0.11 & 0.50 & $\mathbf{3 0 . 7 4}$ & $\mathbf{1 0 0 . 0 0}$ \\
\hline
\end{tabular}

The grid wise spatial distribution of average precipitation for different temporal resolution (annual, seasonal, and monthly) is presented in Figs. 2 and 3. The Fig. 5 presents the five-number summary (minimum, first quartile, mean, third quartile, and maximum) and outliers of spatially averaged precipitation for eight ACRs. The summary is similar to grid wise distribution with Eastern ACR receiving the highest precipitation followed by central and northeastern ACRs and northern and southwestern ACRs receiving minimum precipitation for all time scale. The summer and autumn observed outliers for almost all ACRs and are positively skewed.
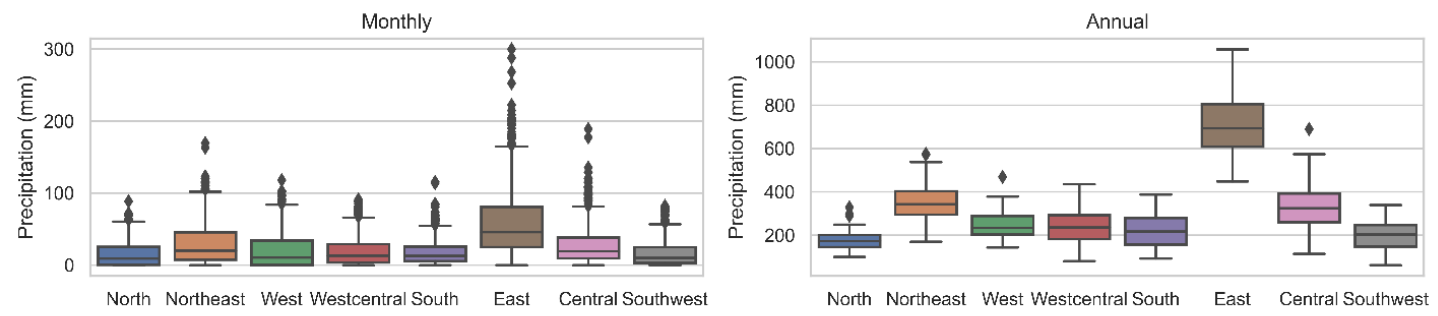

Winter
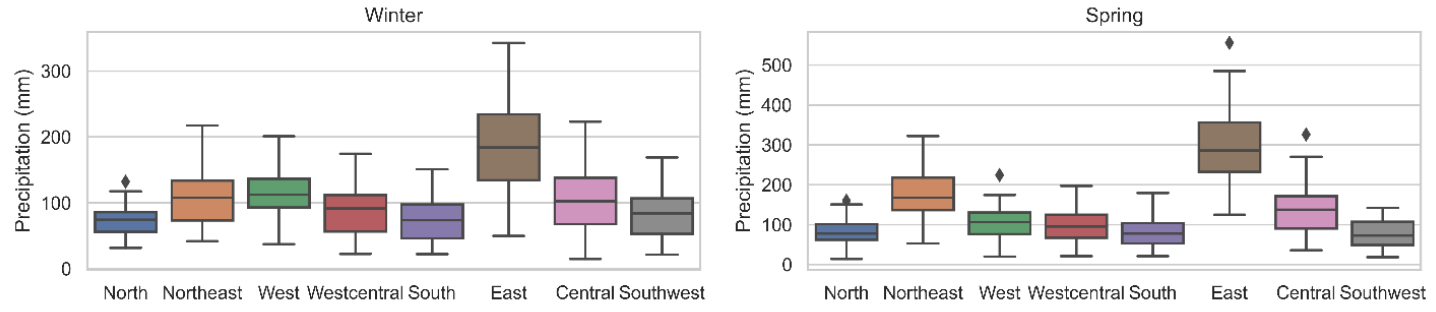

Summer
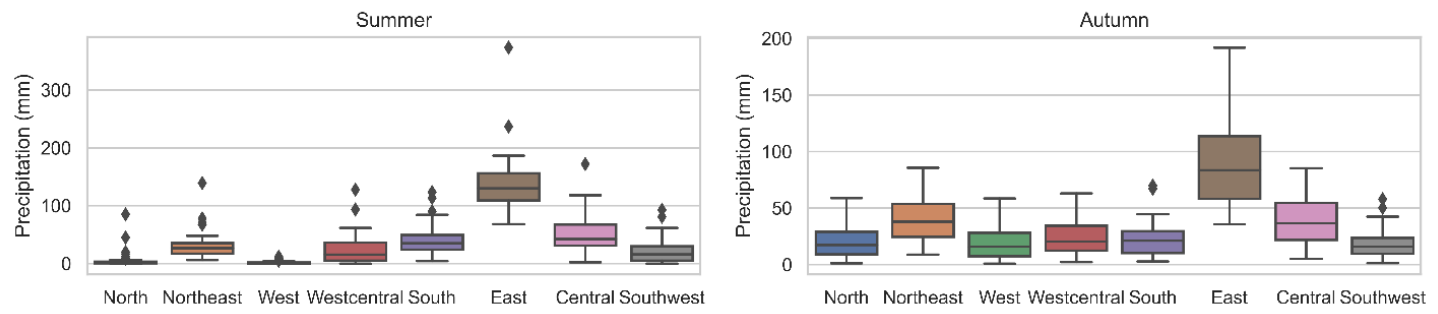

Fig. 5 Box and whisker plots for average monthly, seasonal, and annual precipitation for different ACRs 


\section{Annual and Seasonal Variability in Precipitation}

The spatial patterns of the average annual and seasonal variability in precipitation are presented in Fig. 6 . The provinces in southwestern ACR observed the highest annual precipitation variability ranging between $32.97 \%$ to $51.57 \%$ followed by the central and west-central ACRs between $29.25 \%$ to $40.41 \%$. Less variation can be observed in annual precipitation as we move northeast and east of central ACR. The eastern ACR observed the minimum variability between $18.08 \%$ to $32.97 \%$.

Similarly, the Fig. reveals high interannual variability in the seasonal precipitation ranging between $16.53 \%$ to $>200 \%$ between seasons. The winter and spring seasons demonstrate less variability in precipitation ranging between $16.53 \%$ to $58.36 \%$ for all ACRs compared to the high variability during summer and autumn especially in western, southwestern, and northern ACRs. A cycle of variation occurs in average seasonal precipitation with least variation in winter (DJF), peaking in summer (JJA) then declining in autumn (SON). The highest variability of $204.776 \%$ occurred during summer season in the border of southwestern and western ACRs. The southern, central, and eastern ACR showed the least variation between $16.53 \%$ to $58.36 \%$ in all seasons. High precipitation occurring season and high precipitation receiving regions demonstrated lesser variability compared to the low precipitation receiving regions and during dry seasons (summer and autumn).
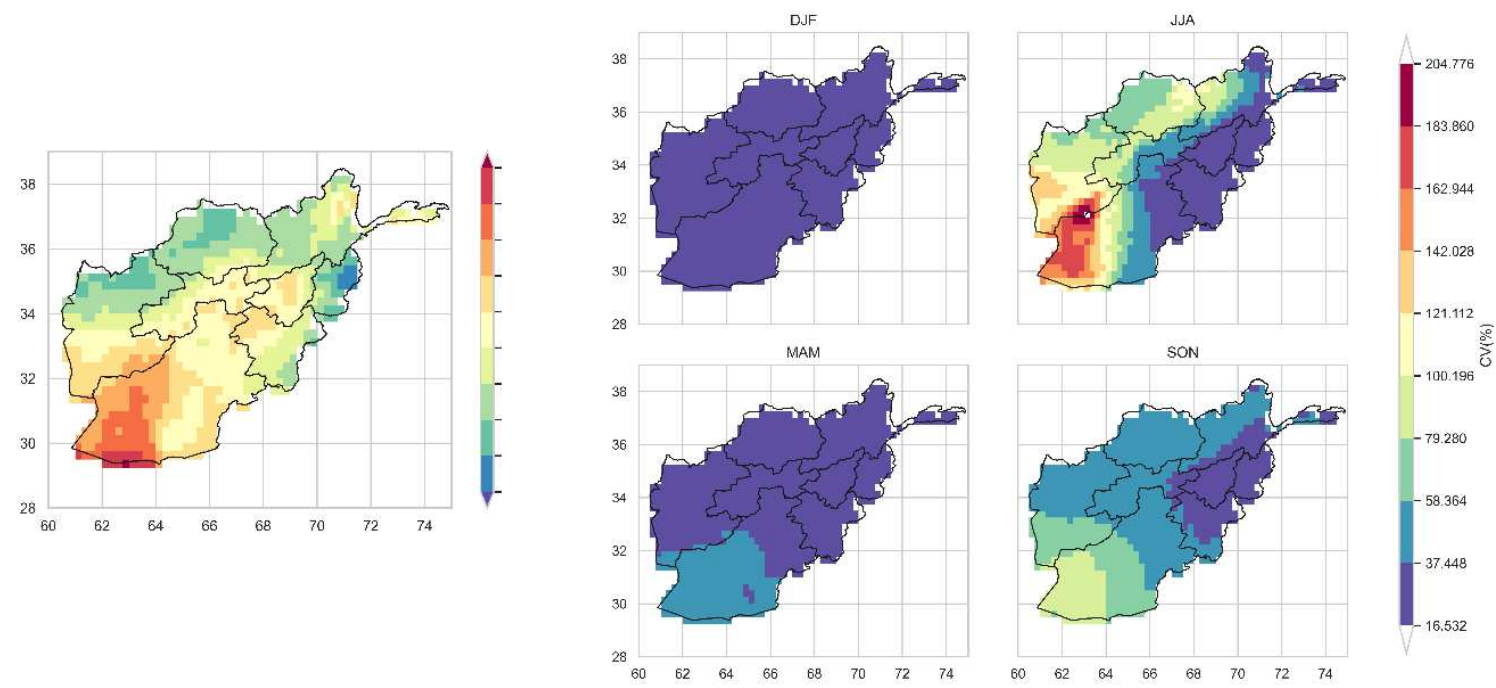

Fig. 6 Spatial variations of average annual (left) and seasonal precipitation (right) across Afghanistan using Coefficient of Variation

\section{Extreme Precipitation Indices}

The averaged spatial distribution of the EPIs across Afghanistan is presented in Fig. 7. It can be seen from the figure that the lower parts of western ACR (Farah province) and southwestern (Nimroz province), observed the CDD(CWD) of $233.75(<3.17)$ days making these regions the driest belt. On an average, the $\operatorname{CDD}(\mathrm{CWD})$ ranged between 142.16 to 165.06 (3.82 to 5.77) days for northern ACR, comparatively dry considering <73.46 (5.77 to 8.37) days of $\mathrm{CDD}(\mathrm{CWD})$ in central and southern ACRs. The eastern ACR is the wettest region with $\mathrm{CDD}(\mathrm{CWD})<50.56(6.42$ to 9.02) days.

Regarding the frequency indices, majority of the ACRs including southwestern, southern, western, westcentral and northern exhibited consistent R20mm with the frequency of $<1$ day. While northeastern ACR observed R20mm between 0.93 to 2.78 days, eastern ACR observed highest frequency of 8.35 days. Likewise, R10mm exhibited similar spatial distribution to R20mm where higher values were obtained in eastern ACR (23.42 days) and northeastern ACR (15.64 days) and lower values were obtained in western and southwestern ACRs ( $<2.69$ days). The average number 
of days receiving very wet day precipitation (R95P) for entire ACRs except Nimroz province of southwestern ACR was 18.27 days. Singular value of 3.67 days for extremely wet precipitation (R99p) was observed for entire nation.

The spatial distribution of intensity indices of Rx 1day and Rx5day followed a similar pattern. The intensity of Rx5day is almost twice the Rx1day intensity in all ACRs. Eastern ACR received highest Rx1day (Rx5day) with the values of 47.42 (98.90) $\mathrm{mm}$. In contrast, the dry southwestern ACR received lowest Rx1day (Rx5day) values of 6.62 (13.16) $\mathrm{mm}$. Similar spatial variability can be observed in annual total wet day precipitation (PRCPTOT) with eastern ACR receiving maximum precipitation value of $848.84 \mathrm{~mm}$ while southwestern ACR receiving lowest PRCPTOT of 50.92 $\mathrm{mm}$ and other regions receiving between 228.23 to $582.87 \mathrm{~mm}$.
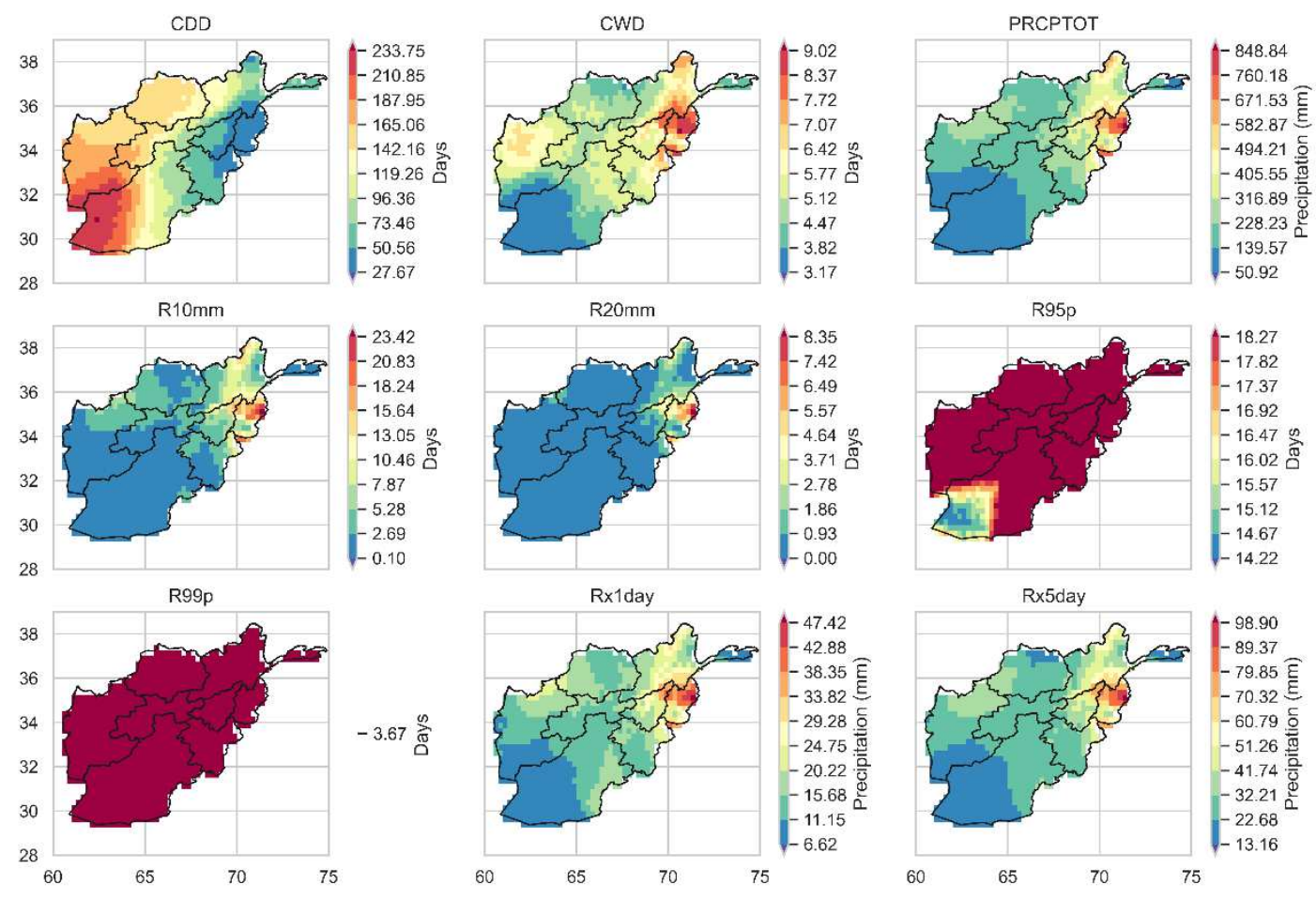

Fig. 7 Map showing spatial distribution of different extreme precipitation indices

\section{Normality Test}

The Shapiro-Wilk and Anderson-Darling normality tests were applied on annual, seasonal, and monthly timeseries at $5 \%$ significance level. The result is presented in Table 7. None of the time series during the months from June to November were normally distributed for all ACRs. Only the month of March witnessed the normality of the data for majority of ACRs (except for northeastern ACR and central ACR). Similarly, only northern, and western ACRs passed both the normality tests for the month of January. While northern, northeastern and eastern ACRs passed both the normality tests, western ACR failed SW for February timeseries. The westcentral ACR passed AD test for December but failed to converge on SW test. All the ACRs except for northern and western ACRs demonstrated the normally distributed annual data series. The precipitation data were normally distributed for all ACRs in spring season and winter season (except for southern ACR). Majority of the ACRs failed both SW and AD tests for summer and autumn seasons. 
Table 7 Normality test for region wise spatially averaged precipitation data for annual, seasonal, and monthly temporal resolution at the significance level of $5 \%$

\begin{tabular}{|c|c|c|c|c|c|c|c|c|c|}
\hline $\begin{array}{l}\text { Months/ } \\
\text { Seasons }\end{array}$ & test & North & Northeast & West & Westcentral & South & East & Central & Southwest \\
\hline \multirow[t]{2}{*}{ Jan } & AD & passed & failed & passed & failed & failed & failed & failed & failed \\
\hline & SW & passed & failed & passed & failed & failed & failed & failed & failed \\
\hline \multirow[t]{2}{*}{ Feb } & AD & passed & passed & passed & failed & failed & passed & failed & failed \\
\hline & SW & passed & passed & Failed & failed & failed & passed & failed & failed \\
\hline \multirow[t]{2}{*}{ Mar } & AD & passed & failed & passed & passed & passed & passed & passed & passed \\
\hline & SW & passed & failed & passed & passed & passed & passed & failed & passed \\
\hline \multirow[t]{2}{*}{ Apr } & AD & passed & failed & Failed & failed & failed & failed & failed & failed \\
\hline & SW & passed & failed & Failed & failed & failed & failed & failed & failed \\
\hline \multirow[t]{2}{*}{ May } & AD & failed & failed & Failed & failed & failed & passed & failed & failed \\
\hline & SW & failed & failed & Failed & failed & failed & failed & failed & failed \\
\hline \multirow[t]{2}{*}{ Jun } & AD & failed & failed & Failed & failed & failed & failed & failed & failed \\
\hline & SW & failed & failed & Failed & failed & failed & failed & failed & failed \\
\hline \multirow[t]{2}{*}{ July } & AD & failed & failed & Failed & failed & failed & failed & failed & failed \\
\hline & SW & failed & failed & Failed & failed & failed & failed & failed & failed \\
\hline \multirow[t]{2}{*}{ Aug } & AD & failed & failed & Failed & failed & failed & failed & failed & failed \\
\hline & SW & failed & failed & Failed & failed & failed & failed & failed & failed \\
\hline \multirow[t]{2}{*}{ Sep } & AD & failed & failed & Failed & failed & failed & failed & failed & failed \\
\hline & SW & failed & failed & Failed & failed & failed & failed & failed & failed \\
\hline \multirow[t]{2}{*}{ Oct } & AD & failed & failed & Failed & failed & failed & failed & failed & failed \\
\hline & SW & failed & failed & Failed & failed & failed & failed & failed & failed \\
\hline \multirow[t]{2}{*}{ Nov } & AD & failed & failed & Failed & failed & failed & failed & failed & failed \\
\hline & SW & failed & failed & Failed & failed & failed & failed & failed & failed \\
\hline \multirow[t]{2}{*}{ Dec } & AD & failed & failed & Failed & passed & failed & failed & failed & failed \\
\hline & SW & failed & failed & Failed & failed & failed & failed & failed & failed \\
\hline \multirow[t]{2}{*}{ Annual } & AD & failed & passed & Failed & passed & passed & passed & passed & passed \\
\hline & SW & failed & passed & Failed & passed & passed & passed & passed & passed \\
\hline \multirow[t]{2}{*}{ Autumn } & AD & failed & passed & Failed & failed & failed & passed & passed & failed \\
\hline & SW & failed & passed & Failed & failed & failed & failed & failed & failed \\
\hline \multirow[t]{2}{*}{ Spring } & AD & passed & passed & passed & passed & passed & passed & passed & passed \\
\hline & SW & passed & passed & passed & passed & failed & passed & passed & passed \\
\hline \multirow[t]{2}{*}{ Summer } & AD & failed & failed & Failed & failed & failed & failed & failed & failed \\
\hline & SW & failed & failed & Failed & failed & failed & failed & failed & failed \\
\hline \multirow[t]{2}{*}{ Winter } & AD & passed & passed & passed & passed & failed & passed & passed & passed \\
\hline & SW & passed & passed & passed & passed & failed & passed & passed & passed \\
\hline
\end{tabular}

\section{Annual, Monthly and Seasonal Trends}


The spatial distribution of the MMK trend test and Sen's slope (only in the region with significant trends at the significance level of 5\%) are presented Figs. 8, 9 and 10.

\section{Annual Trends}

The spatial distribution of the MMK test statistics $(Z)$ and the significance of the trend using Sen's slope estimator is presented in Fig. 8. The northeastern ACR observed highest declining trend in annual precipitation at the rate of -1.5 $\mathrm{mm} /$ year at high hills to $-6 \mathrm{~mm} /$ year along the low lands. Similarly, Farah province in western ACR and Nimroz province in southwestern ACR recorded the declining trend at the rate of 0 to $-1.5 \mathrm{~mm} / \mathrm{year}$. Only Nuristan province in eastern ACR observed the increasing trend of precipitation at the rate of 1.5 to $4.5 \mathrm{~mm} /$ year. Majority of ACRs (northern, central, southern) did not show any trends.
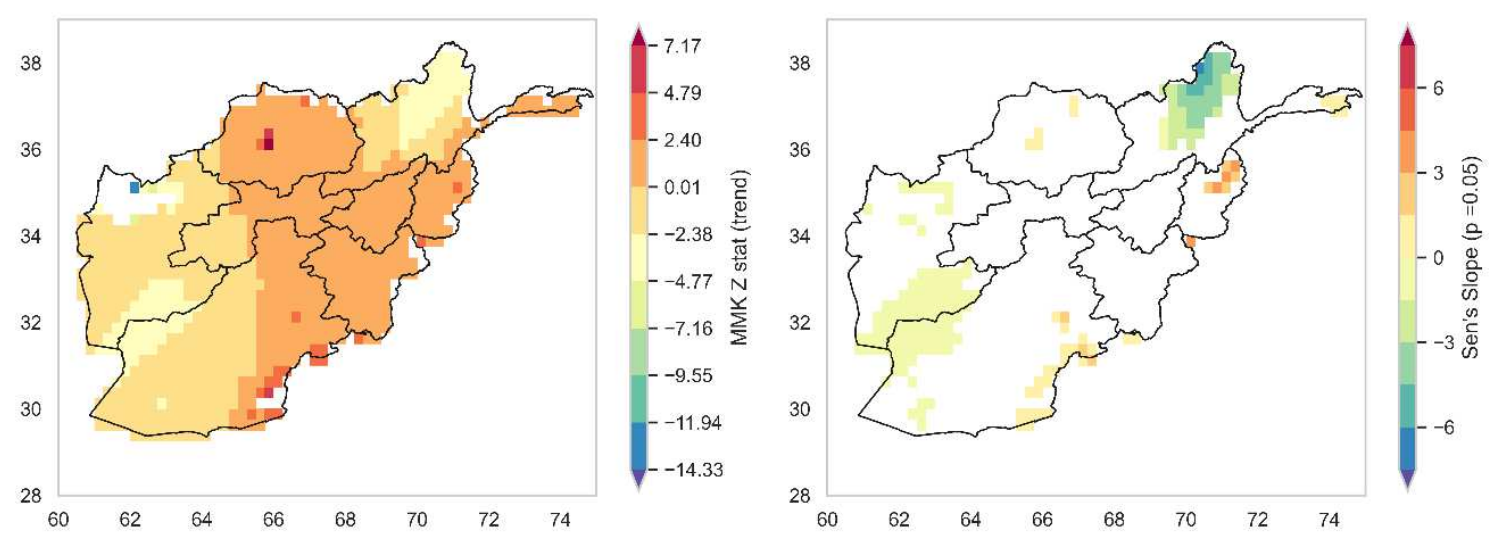

Fig. 8 Maps showing MK - Z statistics (left) and Sen's slope in the region where significant trends were observed at $5 \%$ significance level across Afghanistan

\section{Monthly Trend}

The spatial distribution of the Sen's slope where significant trend was observed at 5\% significance level is presented in the Fig. 9. The noTable changes in trends are concentrated around western, southwestern, central, parts of westcentral, and northeastern ACRs. West corner of southwestern ACR revealed the increasing trend of precipitation during the month of February, April, May, September and November at the rate of $<0.13 \mathrm{~mm} /$ year. Similarly, eastern part of southwestern ACR, central ACR, westcentral ACR northeastern ACR, and eastern ACR observed the increasing trend in the month of June, July, August, and September at the rate ranging between 0.13 to $0.69 \mathrm{~mm} / \mathrm{year}$. In contrast, the Northeastern ACR observed the declining trend in the month of March and partially in the month of April, November and December. The declining trend in northeastern ACR ranges between -0.431 to $>-1.5 \mathrm{~mm} /$ year. 

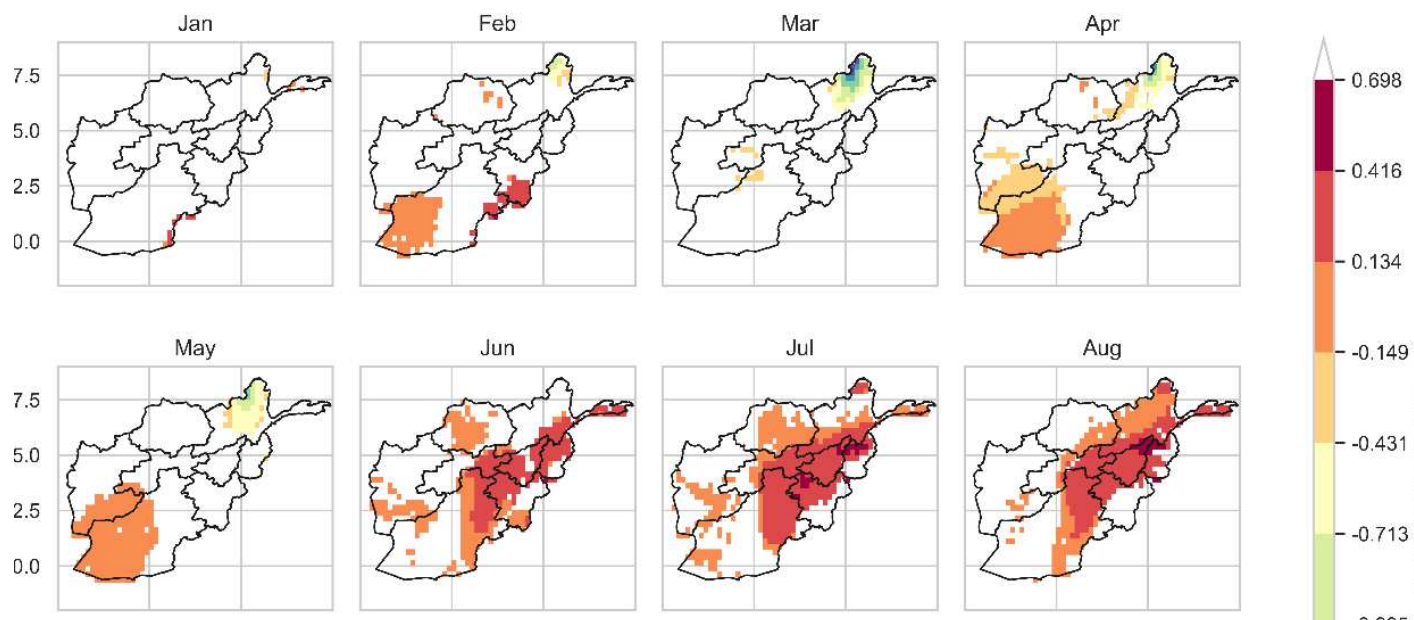

$-0.149$
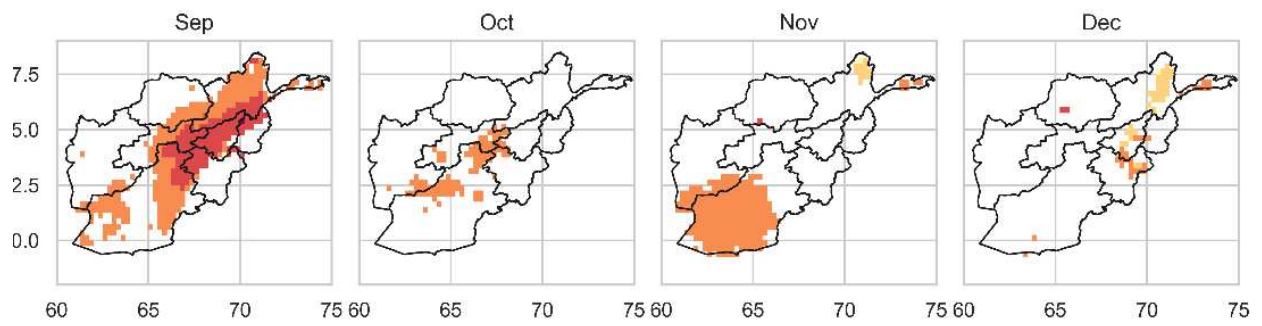

Fig. 9 Spatial distribution of Sen's slope for the monthly precipitation trends only in the regions meeting the criteria for significance level of $5 \%$.

\section{Seasonal Precipitation Trend}

The seasonal spatial trend distribution is presented in Fig. 10. It shows high spatial and temporal variability. Winter (autumn) season observed decreasing (increasing) trends in very few regions especially in northeastern ACR (Uruzgun Province in southwestern ACR and Bamyan in westcentral ACR) at the rate of -0.184 to $-0.03 \mathrm{~mm} / \mathrm{year}$ ( 0 to $0.04 \mathrm{~mm} /$ year). Summer precipitation exhibited the highest increasing trend of $0.19 \mathrm{~mm} /$ year extending east of Kandhar in sourthwestern ACR to southern, central, eastern ACRs and small part of Badakshan province in northeastern ACR at the border of Pakistan. Similarly, spring season exhibited the declining trend. Northeastern ACR observed highest declining trend of -0.18 to $-0.48 \mathrm{~mm} /$ year and parts of Western ACR at the rate of -0.18 to -0.03 mm/year. 

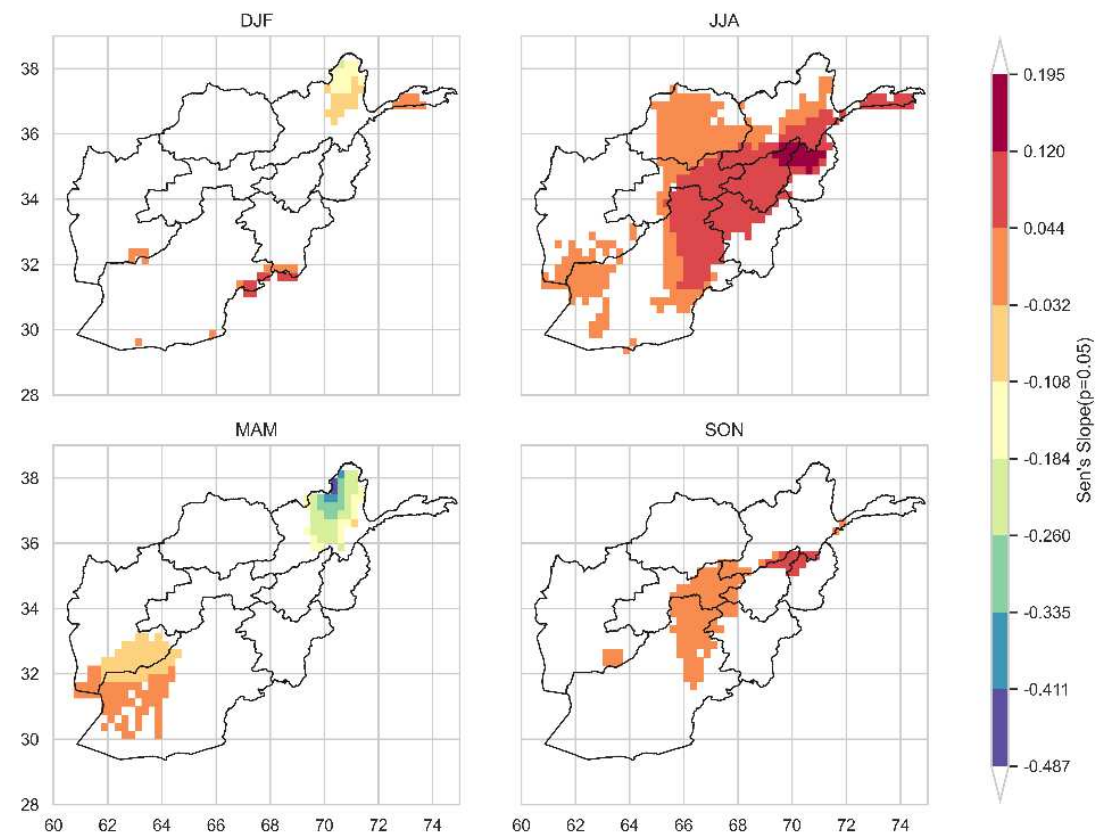

Fig 10 Spatial distribution of seasonal trends across Afghanistan only in regions with significant trend at the significance level of $5 \%$

\section{Trend analysis of extreme indices}

The Nimroz province of southwestern ACR (Bamyan in westcentral and part of central, northeastern, and northern ACRs) showed the significant increase (decrease) in CDD at the rate of 0.65 to 1.64 days/year (-2.82 to -0.34 days/year) as presented in Fig. 11. Likewise, parts of eastern and northeastern ACRs observed the decrease in CWD at the rate ranging between -0.07 to -0.03 days/year.

In terms of frequency indices, the southern corner extending from west to east exhibited the increasing trends in frequency of days receiving high intensity rainfalls: R $10 \mathrm{~mm}$ and $\mathrm{R} 20 \mathrm{~mm}$ at the rate of 0 to 0.23 days/year and 0 to 0.12 days/year respectively. In contrast, parts of northeastern ACRs observed declining trend in R $20 \mathrm{~mm}$ at the rate of -0.02 to -0.33 days/year.

A declining trend was observed for the very wet precipitation days R95p in the southwestern, part of western ACR and northeastern ACR at the rate of -0.15 to $-0.33 \mathrm{~mm} /$ year. Contrastingly, east corners of both eastern and northeastern ACR observed the increasing trend in R95p at the rate of 0.11 to $0.24 \mathrm{~mm} /$ year. Similar pattern was observed for extremely wet precipitation R99p with higher spatial coverage for increasing trend concentrated along the border of Pakistan compared to R95p. Bamyan province of the westcentral ACR and northeastern ACR revealed the declining trend at the rate ranging between -0.03 to $-0.09 \mathrm{~mm} /$ year. On the other hand, the southern corners of southwestern (extending east of Kandhar province), southern and eastern ACRs manifested the increasing trend ranging between 0.03 to $0.09 \mathrm{~mm} /$ year. Further on the intensity indices (Rx1day and Rx5day), resembling patterns of trend to duration and frequency indices were observed. South corners of southwestern (extending east of Kandhar Province), southern, central, and eastern ACRs revealed the increasing trend at the rate ranging between 0.14 to $0.52 \mathrm{~mm} / \mathrm{year}$ for Rx1day and 0.25 to 0.98 for Rx 5 day. Conversely, parts of westcentral, northern and northeastern ACRs ranging between -0.05 to $-0.67 \mathrm{~mm} / \mathrm{year}$ for Rx1day and Rx5day. Regarding PRCPTOT, Nimroz province of southwestern ACR ,Farah province of western ACR and northeastern ACR demonstrated declining trend between 0 to $-6.03 \mathrm{~mm} / \mathrm{year}$. 

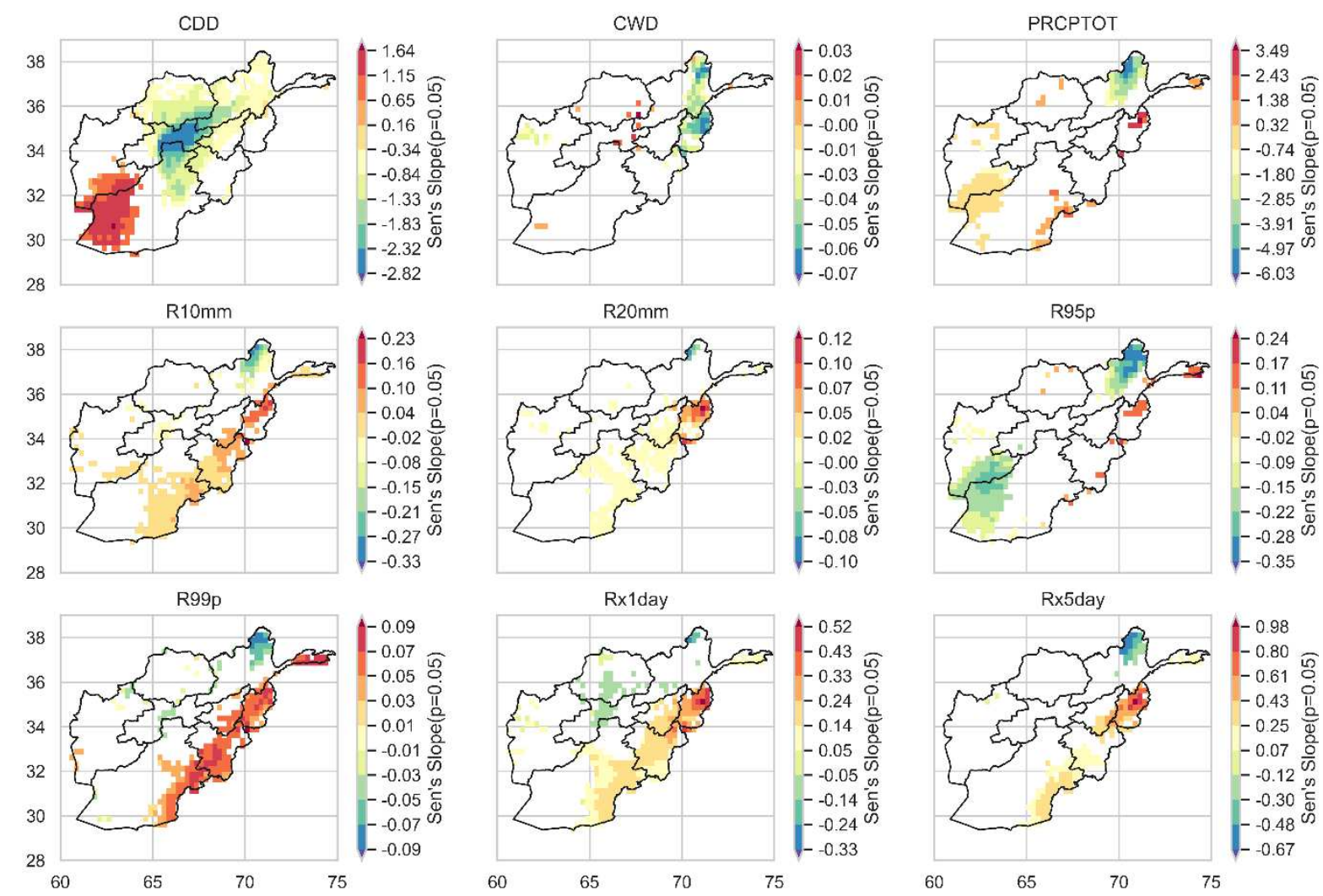

Fig. 11 Map displaying significant trends of extreme precipitation indices at the significance level of $5 \%$ using Sen's slope

\section{Discussion}

This study analyzed the trend in spatial and temporal variability of the precipitation and its extremes across Afghanistan. The spatio-temporal distribution of precipitation is highly heterogeneous in Afghanistan. The eastern ACR receives precipitation more than $800 \mathrm{~mm}$ while scanty precipitation $<100 \mathrm{~mm}$ occurs in southwestern ACR. Similar figuress were reported in earlier studies (NEPA 2016). It revealed high annual and seasonal variability in precipitation. The ACRs receiving higher amount of precipitation showed less variability compared deserted regions with less precipitation.

Afghanistan did not exhibit significant annual trend in precipitation for most regions rather decreasing trend was observed in isolated clusters. The negative trend of annual precipitation in southwestern and northeastern ACRs and insignificant in other ACRs is similar to the findings of (Aich et al. 2017; Haag et al. 2019). Decreasing trends were also reported in semi-arid and arid regions of Iran bordering Afghanistan in west (Modarres and de Paulo Rodrigues da Silva 2007; Tabari et al. 2012). The increasing (decreasing) trend of the summer (spring) precipitation in the northeastern ACR and increasing trend of summer precipitation in eastern and central ACRs is consistent with (Haag et al. 2019). Most of the Afghani in rural areas rely on rain-fed agriculture system. Thus, winter and spring precipitation play an important role in Afghanistan as they contribute to more than $75 \%$ of the annual total precipitation. The northeastern region observing declining precipitation trend is likely to have impact on the agriculture as $22 \%$ of the total arable land area belongs to this ACR. The west ward shift of the South Asian High could be one of the reasons for increasing trend in the eastern region during summer (Wei et al. 2014). The increasing precipitation trend in summer season at the rate of 0.08 to $0.16 \mathrm{~mm} / \mathrm{year}$ in the Wakhan corridor and small part near the border of Pakistan in northeastern, eastern and central ACRs is likely to aggravate the avalanche and flash floods. The risk profile prepared by The World Bank Group (2017) The World Bank (2017) indicated aforementioned regions 
at high risk of floods and avalanche. Studies carried out in Pakistan revealed upward annual precipitation trend in the northern Highland and sub-Himalayan ranges (Ahmed et al. 2017; Iqbal et al. 2019; Hussain and Lee 2013).

The extreme intensity indices- Rx1day and Rx5day and frequency indices-R10mm, R20mm and R95p were decreasing (increasing) significantly across northeast of the westcentral ACR (eastern and southern ACRs). Similar results were reported by (Zhan et al. 2017) in their study related to changes in extreme precipitation events over HinduKush Himalayan region. Similarly, increase (decrease) in CDD in southwestern ACR (westcentral ACR) is presented in the study by Zhang and Liang (2020). The increase of extreme intensity and frequency indices is likely to exacerbate the events of flashfloods in eastern and southern ACRs. In addition, extreme events have impact on agriculture and infrastructure especially in regions with strong relief like northern, northeastern, central and eastern ACRs (Qutbudin et al. 2019). More than 100,000 people are affected each year by flooding (Ginnetti and Lavell 2015). The increase of CDD is linked to droughts. Series of lasting drought events in the past (1963-64; 1966-67;1970-72;1998-2006) were already reported (Přívara and Prrívarová 2019). Further increasing trend of CDD in southwestern ACR and decreasing PRCPTOT in northeastern and southwestern ACRs are expected to affect the cropping pattern and production by altering the water availability for irrigation fueling the drought frequency. Natural disaster induced migration is regular in Afghanistan especially to informal settlements along the provincial centers and along the dry river beds.

The study presents the precipiation trend analysis in the Afghanistan along with extreme indices with the use of finer spatial resolution data for the similar time frame. The validation of the study is limited to the results of previous studies as observed data are unavaialbe for evaluation of used gridded data set. Though the reanalyzed dataset could represent the regional climate variable but may not reflect the local extremes. Obtained results were mostly consistent with previous studies except for the trend in spring precipitation with Qutbudin et al. (2019). The inconsistency in results could be an outcome different dataset use (Nashwan et al. 2019) and time windows (Ngongondo et al. 2011) used in studies. The uncertainty in trend for the gridded data results mainly due to the method used in producing gridded data, number of observations used, and method of interpolation or model used for reanalysis. Lack of quality long term observed precipitation time series to validate the gridded data, plethora of gridded dataset availability to choose from with inherent uncertainty, and resolution of dataset further posed significant challenge in this study.

\section{Conclusion}

Understanding precipitation variability and extremes at different spatial and temporal resolution is core to sustainable water resources management and disaster risk reduction. It plays vital role for countries like Afghanistan which is highly vulnerable to climate change and majority of its population dependent on sustenance agriculture (Jawid \& Khadjavi, 2019). This study mapped the spatio-temporal trends in precipitation and its extremes in the country for the period of 60 years from 1951 to 2010. Robust non-parametric trend analysis techniques were applied to APHRODITE gridded dataset of $0.25^{\circ} \mathrm{X} 0.25^{\circ}$ spatial resolution due to unavailability of long term observed data.

Trend analysis data showed precipitation reduction and increased number of CDD in northeastern and southwestern ACRs especially in spring season. This declining trend is sought to intensify the drought events affecting the water availability and agricultural production. In contrast, the increasing trend of summer precipitation and frequency of very heavy $(\mathrm{R} 10 \mathrm{~mm})$ and extremely heavy precipitation $(\mathrm{R} 20 \mathrm{~mm})$ in the central, eastern, and southern ACRs are anticipated to aggravate flooding events. The trend change could be Natural Oscillation induced or human induced climate which suggest further research is required. Given that the large population is dependent on the sustenance rain-fed agriculture, sequences of series of droughts and frequent flooding in recent days, the reflection of results into the natural disaster preparedness planning, water resources planning and sustainable agriculture design.

\section{Declarations}

\section{Funding}

This work did not receive any funding and support from any organization. 


\section{Conflict of interest}

The authors declare no conflict of interest.

\section{Availability of data and material}

The datasets generated during and/or analyzed during the current study are available on reasonable request from the corresponding author.

\section{Code Availability}

The codes written for the current study are available on reasonable request from the corresponding author.

\section{Author information}

\section{Affiliations}

1. Department of Forestry and Natural Resources, Faculty of Agriculture, Bamyan University, Bamyan 1601, Afghanistan

Qurban Aliyar

2. Water Engineering and Management, School of Engineering and Technology, Asian Institute of Technology, P.O. Box 4 Klong Luang, Pathum Thani, 12120, Thailand.

Santosh Dhungana

3. Water Engineering and Management, School of Engineering and Technology, Asian Institute of Technology, P.O. Box 4 Klong Luang, Pathum Thani, 12120, Thailand.

Sangam Shrestha

\section{Authors' Contributions}

Conceptualization: Quarban Aliyar and Santosh Dhungana; Methodology: Santosh Dhungana; Software: Santosh Dhungana; Validation: Santosh Dhungana, Quarban Aliyar and Sangam Shrestha; Formal analysis: Santosh Dhungana and Quarban Aliyar; Investigation: Santosh Dhungana; Resources: Quarban Aliyar and Santosh Dhungana; Data curation: Quarban Aliyar; Writing-original draft preparation: Santosh Dhungana; Writing-review and editing: Quarban Aliyar, Santosh Dhungana and Sangam Shrestha; Visualization: Santosh Dhungana; Supervision: Sangam Shrestha.

\section{Corresponding author}

Correspondence to Santosh Dhungana

\section{Ethics declarations}

\section{Ethics Approval}

Not applicable

\section{Consent for publication}

All authors have read and agreed to the published version of the manuscript. To the Theoretical and Applied Climatology journal editorial team, all authors listed immediately below have participated in conception and design or analysis and interpretation of the data; drafting the article or revising it critically for important intellectual content and approval of the final revised version.

1. Quarban Aliyar 
2. Santosh Dhungana (corresponding author)

3. Sangam Shrestha

\section{Consent to participate}

Not applicable

\section{References}

Aamir E, Hassan I Trend analysis in precipitation at individual and regional levels in Baluchistan, Pakistan. In: IOP Conference Series: Materials Science and Engineering, 2018. vol 1. IOP Publishing, p 012042

Aawar T, Khare D, Singh L (2019) Identification of the trend in precipitation and temperature over the Kabul River sub-basin: a case study of Afghanistan. Modeling Earth Systems and Environment 5 (4):1377-1394. doi:10.1007/s40808-019-00597-9

Ahmed K, Shahid S, Chung ES, Ismail T, Wang XJ (2017) Spatial distribution of secular trends in annual and seasonal precipitation over Pakistan. Climate Research 74 (2):95-107

Aich V, Akhundzadah NA, Knuerr A, Khoshbeen AJ, Hattermann F, Paeth H, Scanlon A, Paton EN (2017) Climate Change in Afghanistan Deduced from Reanalysis and Coordinated Regional Climate Downscaling Experiment (CORDEX)-South Asia Simulations. Climate 5 (2). doi:ARTN 3810.3390/cli5020038

Akhundzadah NA, Soltani S, Aich V (2020) Impacts of Climate Change on the Water Resources of the Kunduz River Basin, Afghanistan. Climate 8 (10). doi:10.3390/cli8100102

Alexander LV, Zhang X, Peterson TC, Caesar J, Gleason B, Klein Tank AMG, Haylock M, Collins D, Trewin B, Rahimzadeh F, Tagipour A, Rupa Kumar K, Revadekar J, Griffiths G, Vincent L, Stephenson DB, Burn J, Aguilar E, Brunet M, Taylor M, New M, Zhai P, Rusticucci M, Vazquez-Aguirre JL (2006) Global observed changes in daily climate extremes of temperature and precipitation. Journal of Geophysical Research: Atmospheres 111 (D5). doi:https://doi.org/10.1029/2005JD006290

Anderson TW, Darling DA (1954) A Test of Goodness of Fit. Journal of the American Statistical Association 49 (268):765-769. doi:10.1080/01621459.1954.10501232

Bhatti AS, Wang G, Ullah W, Ullah S, Fiifi Tawia Hagan D, Kwesi Nooni I, Lou D, Ullah I (2020) Trend in Extreme Precipitation Indices Based on Long Term In Situ Precipitation Records over Pakistan. Water 12 (3):797

Cannarozzo M, Noto LV, Viola F (2006) Spatial distribution of rainfall trends in Sicily (1921-2000). Physics and Chemistry of the Earth, Parts A/B/C 31 (18):1201-1211. doi:https://doi.org/10.1016/j.pce.2006.03.022

Dai A, Fung IY, Del Genio AD (1997) Surface Observed Global Land Precipitation Variations during 1900-88. Journal of Climate 10 (11):2943-2962. doi:10.1175/1520-0442(1997)010<2943:SOGLPV>2.0.CO;2

Deng X, Nie S, Deng W, Cao W (2018) Statistical evaluation of the performance of gridded monthly precipitation products from reanalysis data, satellite estimates, and merged analyses over China. Theoretical and Applied Climatology 132 (1):621-637. doi:10.1007/s00704-017-2105-x

Easterling DR, Meehl GA, Parmesan C, Changnon SA, Karl TR, Mearns LO (2000) Climate extremes: observations, modeling, and impacts. Science (New York, NY) 289 (5487):2068-2074. doi:10.1126/science.289.5487.2068

Ghulami M, Babel MS, Singh Shrestha M (2017) Evaluation of gridded precipitation datasets for the Kabul Basin, Afghanistan. International Journal of Remote Sensing 38 (11):3317-3332. doi:10.1080/01431161.2017.1294775

Ginnetti J, Lavell C (2015) The risk of disaster-induced displacement in South-Asia. . Geneva

Haag I, Jones PD, Samimi C (2019) Central Asia's Changing Climate: How Temperature and Precipitation Have Changed across Time, Space and Altitude. climate 7 (10)

Hamed KH, Ramachandra Rao A (1998) A modified Mann-Kendall trend test for autocorrelated data. Journal of Hydrology 204 (1-4):182-196. doi:10.1016/s0022-1694(97)00125-x

Hussain M, Mahumud I (2019) pyMannKendall: a python package for non parametric Mann Kendall family of trend tests. Journal of Open Source Software 4 (39):1556

Hussain MS, Lee S (2013) The regional and the seasonal variability of extreme precipitation trends in Pakistan. AsiaPacific Journal of Atmospheric Sciences 49 (4):421-441. doi:10.1007/s13143-013-0039-5

Iqbal Z, Shahid S, Ahmed K, Ismail T, Nawaz N (2019) Spatial distribution of the trends in precipitation and precipitation extremes in the sub-Himalayan region of Pakistan. Theoretical and Applied Climatology 137 (3):2755-2769. doi:10.1007/s00704-019-02773-4

Javari M (2016) Trend and Homogeneity Analysis of Precipitation in Iran. Climate 4 (3):44 
Jawid A, Khadjavi M (2019) Adaptation to climate change in Afghanistan: Evidence on the impact of external interventions. Economic Analysis and Policy 64:64-82. doi:https://doi.org/10.1016/j.eap.2019.07.010

Kim I-W, Oh J, Woo S, Kripalani RH (2019) Evaluation of precipitation extremes over the Asian domain: observation and modelling studies. Climate Dynamics 52 (3):1317-1342. doi:10.1007/s00382-018-4193-4

Klein Tank AMG, Peterson TC, Quadir DA, Dorji S, Zou X, Tang H, Santhosh K, Joshi UR, Jaswal AK, Kolli RK, Sikder AB, Deshpande NR, Revadekar JV, Yeleuova K, Vandasheva S, Faleyeva M, Gomboluudev P, Budhathoki KP, Hussain A, Afzaal M, Chandrapala L, Anvar H, Amanmurad D, Asanova VS, Jones PD, New MG, Spektorman T (2006) Changes in daily temperature and precipitation extremes in central and south Asia. Journal of Geophysical Research: Atmospheres 111 (D16). doi:https://doi.org/10.1029/2005JD006316

Krishnakumar KN, Rao G, Gopakumar Cs (2009) Rainfall trends in twentieth century over Kerala, India. Atmospheric Environment 43:1940-1944. doi:10.1016/j.atmosenv.2008.12.053

Lauri H, Rasanen TA, Kummu M (2014) Using Reanalysis and Remotely Sensed Temperature and Precipitation Data for Hydrological Modeling in Monsoon Climate: Mekong River Case Study. Journal of Hydrometeorology 15 (4):1532-1545. doi:10.1175/Jhm-D-13-084.1

Li-Ge C, Jun Z, Bu-Da S, Jian-Qing Z, Gemmer M (2013) Probability Distribution and Projected Trends of Daily Precipitation in China. Advances in Climate Change Research 4 (3):153-159. doi:10.3724/sp.J.1248.2013.153

Li Z, Yang D, Hong Y (2013) Multi-scale evaluation of high-resolution multi-sensor blended global precipitation products over the Yangtze River. Journal of Hydrology 500:157-169. doi:https://doi.org/10.1016/j.jhydrol.2013.07.023

MAAH, FAO (2003) Agriculture and Food Production in Post-War Afghanistan. Ministry of Agriculture and Animal Husbandry, Afghanistan and FAO, Kabul

Malik A, Kumar A (2020) Spatio-temporal trend analysis of rainfall using parametric and non-parametric tests: case study in Uttarakhand, India. Theoretical and Applied Climatology 140 (1):183-207. doi:10.1007/s00704019-03080-8

Mann HB (1945) Nonparametric Tests Against Trend. Econometrica 13 (3):245-259. doi:doi:10.2307/1907187

Manton MJ, Della-Marta PM, Haylock MR, Hennessy KJ, Nicholls N, Chambers LE, Collins DA, Daw G, Finet A, Gunawan D, Inape K, Isobe H, Kestin TS, Lefale P, Leyu CH, Lwin T, Maitrepierre L, Ouprasitwong N, Page CM, Pahalad J, Plummer N, Salinger MJ, Suppiah R, Tran VL, Trewin B, Tibig I, Yee D (2001) Trends in extreme daily rainfall and temperature in Southeast Asia and the South Pacific: 1961-1998. 21 (3):269284. doi:https://doi.org/10.1002/joc.610

McSweeney C, New M, Lizcano G, Lu X (2010) The UNDP Climate Change Country Profiles: Improving the Accessibility of Observed and Projected Climate Information for Studies of Climate Change in Developing Countries. Bulletin of the American Meteorological Society 91 (2):157-166. doi:10.1175/2009BAMS2826.1

Mendelsohn R, Dinar A, Williams L (2006) The distributional impact of climate change on rich and poor countries. Environment and Development Economics 11 (2):159-178. doi:10.1017/S1355770X05002755

Mendes M, Pala A (2003) Type I Error Rate and Power of Three Normality Tets. Pakistan Journal of Information and Technology 2 (2):135-139

Merino A, García-Ortega E, Navarro A, Fernández-González S, Tapiador FJ, Sánchez JL (2021) Evaluation of gridded rain-gauge-based precipitation datasets: Impact of station density, spatial resolution, altitude gradient and climate. International Journal of Climatology 41 (5):3027-3043. doi:https://doi.org/10.1002/joc.7003

Meshram SG, Singh SK, Meshram C, Deo RC, Ambade B (2018) Statistical evaluation of rainfall time series in concurrence with agriculture and water resources of Ken River basin, Central India (1901-2010). Theoretical and Applied Climatology 134 (3):1231-1243. doi:10.1007/s00704-017-2335-y

Ministry of Agriculture Irrigation and Livestock (2017) Climate Change Adaptation Project.

Modarres R, de Paulo Rodrigues da Silva V (2007) Rainfall trends in arid and semi-arid regions of Iran. Journal of Arid Environments 70 (2):344-355. doi:https://doi.org/10.1016/j.jaridenv.2006.12.024

Myhre G, Alterskjær K, Stjern CW, Hodnebrog Ø, Marelle L, Samset BH, Sillmann J, Schaller N, Fischer E, Schulz M, Stohl A (2019) Frequency of extreme precipitation increases extensively with event rareness under global warming. Scientific Reports 9 (1):16063. doi:10.1038/s41598-019-52277-4

Nashwan MS, Shahid S, Wang X (2019) Uncertainty in Estimated Trends Using Gridded Rainfall Data: A Case Study of Bangladesh. Water 11 (2):349

NEPA (2016) Afghanistan: Climate change science perspectives. Kabul: National Environmental Protection Agency. Kabul

Ngongondo C, Xu C-Y, Gottschalk L, Alemaw B (2011) Evaluation of spatialand temporal characteristics of rainfall in Malawi: a case fo data scarce region. Theoretical and Applied Climatology 106:79-93 
Nguyen P, Thorstensen A, Sorooshian S, Hsu K, Aghakouchak A, Ashouri H, Tran H, Braithwaite D (2018) Global Precipitation Trends across Spatial Scales Using Satellite Observations. Bulletin of the American Meteorological Society 99 (4):689-697. doi:10.1175/BAMS-D-17-0065.1

Nkunzimana A, Bi S, Alriah MAA, Zhi T, Kur NAD (2020) Comparative Analysis of the Performance of SatelliteBased Rainfall Products Over Various Topographical Unities in Central East Africa: Case of Burundi. Earth and Space Science 7 (5):e2019EA000834. doi:https://doi.org/10.1029/2019EA000834

Ongoma V, Chen H, Gao C, Nyongesa AM, Polong F (2018) Future changes in climate extremes over Equatorial East Africa based on CMIP5 multimodel ensemble. Natural Hazards 90 (2):901-920. doi:10.1007/s11069-0173079-9

Ososkova T, Gorelkin N, Chub V (2000) Water Resources of Central Asia and Adaptation Measures for Climate Change. Environmental Monitoring and Assessment 61 (1):161-166. doi:10.1023/A:1006394808699

Piyoosh AK, Ghosh SK (2017) Effect of autocorrelation on temporal trends in rainfall in a valley region at the foothills of Indian Himalayas. Stochastic Environmental Research and Risk Assessment 31 (8):2075-2096. doi:10.1007/s00477-016-1347-y

Praveen B, Talukdar S, Shahfahad, Mahato S, Mondal J, Sharma P, Islam ARMT, Rahman A (2020) Analyzing trend and forecasting of rainfall changes in India using non-parametrical and machine learning approaches. Scientific Reports 10 (1):10342. doi:10.1038/s41598-020-67228-7

Př́vara A, Př́varová M (2019) Nexus between Climate Change, Displacement and Conflict: Afghanistan Case. Sustainability 11 (20). doi:10.3390/su11205586

Qutbudin I, Shiru MS, Sharafati A, Ahmed K, Al-Ansari N, Yaseen ZM, Shahid S, Wang XJ (2019) Seasonal Drought Pattern Changes Due to Climate Variability: Case Study in Afghanistan. Water 11 (5):1096. doi:ARTN 109610.3390/w11051096

Rai A, Saha SK, Pokhrel S, Sujith K, Halder S (2015) Influence of preonset land atmospheric conditions on the Indian summer monsoon rainfall variability. 120 (10):4551-4563. doi:https://doi.org/10.1002/2015JD023159

Razali NM, Wah YB Power comparisions of some selected normality tests. In: Proceedings of the Regional Conference on Statistical Sceinces 2010, Malaysia, 2010. Malaysia Institute of Statistics, Faculty of Computer and Mathematical Sciences, Universiti Teknologi MARA, pp 126-138

Royston JP (1982) Algorithm AS 181: The W Test for Normality. Journal of the Royal Statistical Society Series C (Applied Statistics) 31 (2):176-180. doi:10.2307/2347986

Saini A, Sahu N, Kumar P, Nayak S, Daun W, Avtar R, Behera S (2020) Advanced Rainfall Trend Analysis of 117 Years over West Coast Plain and Hill Agro-Climatic Region of India. Atmosphere 11:1-25

Schönwiese CD, Rapp J (2013) Climate trend atlas of Europe based on observations 1891-1990. Springer Science \& Business Media

Sediqi MN, Shiru MS, Nashwan MS, Ali R, Abubaker S, Wang X, Ahmed K, Shahid S, Asaduzzaman M, Manawi SM (2019) Spatio-Temporal Pattern in the Changes in Availability and Sustainability of Water Resources in Afghanistan. Sustainability 11 (20). doi:10.3390/su11205836

Sen PK (1968) Estimates of the Regression Coefficient Based on Kendall's Tau. Journal of the American Statistical Association 63 (324):1379-1389. doi:10.2307/2285891

Shapiro SS, Wilk MB (1965) An Analysis of Variance Test for Normality (Complete Samples). Biometrika 52 (3/4):591-611. doi:10.2307/2333709

Sheikh MM, Manzoor N, Ashraf J, Adnan M, Collins D, Hameed S, Manton MJ, Ahmed AU, Baidya SK, Borgaonkar HP, Islam N, Jayasinghearachchi D, Kothawale DR, Premalal KHMS, Revadekar JV, Shrestha ML (2015) Trends in extreme daily rainfall and temperature indices over South Asia. International Journal of Climatology 35 (7):1625-1637. doi:https://doi.org/10.1002/joc.4081

Shokory JAN, Tsutsumi J-i, Yamada H, Klöve B (2017) Intra-seasonal Variation of Rainfall and Climate Characteristics in Kabul River Basin. Central Asian Journal of Water Research (CAJWR) 3(2):24-40

Stockholm Environment Institute (2009) Socio-economic Impacts of Climate Change in Afghanistan. Stockholm: Stockholm Environment Institute.

Sun Q, Zhang X, Zwiers F, Westra S, Alexander LV (2021) A Global, Continental, and Regional Analysis of Changes in Extreme Precipitation. Journal of Climate 34 (1):243-258. doi:10.1175/JCLI-D-19-0892.1

Tabari H, Abghari H, Hosseinzadeh Talaee P (2012) Temporal trends and spatial characteristics of drought and rainfall in arid and semiarid regions of Iran. Hydrological Processes 26 (22):3351-3361. doi:https://doi.org/10.1002/hyp.8460

Taylor KE (2001) Summarizing multiple aspects of model performance in a single diagram. Journal of Geophysical Research: Atmospheres 106 (D7):7183-7192. doi:https://doi.org/10.1029/2000JD900719 
The World Bank Group (2017) Disaster Risk Profile Afghanistan Washington D.C.

The World Bank Group, The Asian Development Bank (2020) Climate Risk Country Profile: Afghanistan. Washington

TÜNNERMEIER T, HOUBEN G (2005) Hydrogeology of Kabul Basin Part I: Geology, aquifer characteristics, climate and hydrography. Report for the project " Improving groundwater protection for the preventative avoidance of drought problems in Kabul Basin, Afghanistan". Federal Institute for Geosciences and Natural Resources (BGR), Hannover

Unger-Shayesteh K, Vorogushyn S, Farinotti D, Gafurov A, Duethmann D, Mandychev A, Merz B (2013) What do we know about past changes in the water cycle of Central Asian headwaters? A review. Global and Planetary Change 110:4-25. doi:https://doi.org/10.1016/j.gloplacha.2013.02.004

Wei W, Zhang R, Wen M, Rong X, Li T (2014) Impact of Indian summer monsoon on the South Asian High and its influence on summer rainfall over China. Climate Dynamics 43 (5):1257-1269. doi:10.1007/s00382-0131938-y

Xie P, Chen M, Yang S, Yatagai A, Hayasaka T, Fukushima Y, Liu C (2007) A Gauge-Based Analysis of Daily Precipitation over East Asia. Journal of Hydrometeorology 8 (3):607-626. doi:10.1175/JHM583.1

Xu ZX, Takeuchi K, Ishidaira H, Li JY (2005) Long-term trend analysis for precipitation in Asian Pacific FRIEND river basins. Hydrological Processes 19 (18):3517-3532. doi:https://doi.org/10.1002/hyp.5846

Xuebin Zhang LA, Gabriele C. Hegerl, Philip Jones, Albert Klein Tank, Thomas C. Peterson, Blair Trewin, Francis W. Zwiers (2011) Indices for monitoring changes in extremes based on daily temperature and precipitation data. Wires Climate Change 2 (6):851-870. doi:https://doi.org/10.1002/wcc.147

Yang Y, Tang J, Xiong Z, Dong X (2017) Evaluation of High-Resolution Gridded Precipitation Data in Arid and Semiarid Regions: Heihe River Basin, Northwest China. Journal of Hydrometeorology 18 (12):3075-3101. doi:10.1175/JHM-D-16-0252.1

Yatagai A, Kamiguchi K, Arakawa O, Hamada A, Yasutomi N, Kitoh A (2012) APHRODITE: Constructing a LongTerm Daily Gridded Precipitation Dataset for Asia Based on a Dense Network of Rain Gauges. Bulletin of the American Meteorological Society 93 (9):1401-1415. doi:10.1175/BAMS-D-11-00122.1

Yeggina S, Teegavarapu RSV, Muddu S (2020) Evaluation and bias corrections of gridded precipitation data for hydrologic modelling support in Kabini River basin, India. Theoretical and Applied Climatology 140 (3):1495-1513. doi:10.1007/s00704-020-03175-7

Zhai P, Sun A, Ren F, Liu X, Gao B, Zhang Q (1999) Changes of Climate Extremes in China. Weather and Climate Extremes. Springer, Dordrecht. doi:https://doi.org/10.1007/978-94-015-9265-9 13

Zhai P, Zhang X, Wan H, Pan X (2005) Trends in Total Precipitation and Frequency of Daily Precipitation Extremes over China. Journal of Climate 18 (7):1096-1108. doi:10.1175/JCLI-3318.1

Zhan YJ, Ren GY, Shrestha AB, Rajbhandari R, Ren YY, Sanjay J, Xu Y, Sun XB, You QL, Wang S (2017) Changes in extreme precipitation events over the Hindu Kush Himalayan region during 1961-2012. Advances in Climate Change Research 8 (3):166-175. doi:10.1016/j.accre.2017.08.002

Zhang X, Alexander L, Hegerl GC, Jones P, Tank AK, Peterson TC, Trewin B, Zwiers FW (2011) Indices for monitoring changes in extremes based on daily temperature and precipitation data. WIREs Climate Change 2 (6):851-870. doi:https://doi.org/10.1002/wcc.147

Zhang Y, Liang C (2020) Analysis of Annual and Seasonal Precipitation Variation in the Qinba Mountain area, China. Scientific Reports 10 (1):961. doi:10.1038/s41598-020-57743-y

Zhou B, Liang C, Zhao P, Dai Q (2018) Analysis of Precipitation Extremes in the Source Region of the Yangtze River during 1960-2016. 10 (11):1691 